\title{
Modelling the technical potential of bioelectricity production under land use constraints: A multi-region Brazil case study
}

Lucas Lyrio de Oliveira ${ }^{\mathrm{a},=}{ }^{2}$ van Garcia Kerdan ${ }^{\mathrm{b}, \mathrm{e}, \mathrm{f},=, 1}$, Celma de Oliveira Ribeiro ${ }^{\mathrm{a}}$, Claudio Augusto Oller do Nascimento ${ }^{\mathrm{c}}$, Erik Eduardo Rego ${ }^{\mathrm{a}}$, Sara Giarola ${ }^{\mathrm{d}}$, Adam Hawkes ${ }^{\mathrm{b}}$

\author{
a Department of Production Engineering, Polytechnic School of the University of Sao Paulo, Sao Paulo, \\ Brazil \\ ${ }^{\mathrm{b}}$ Department of Chemical Engineering, Imperial College London, London, United Kingdom \\ ${ }^{c}$ Department of Chemical Engineering, Polytechnic School of the University of Sao Paulo, Sao Paulo, \\ Brazil \\ ${ }^{\mathrm{d}}$ Department of Earth Science \& Engineering, Imperial College London, London, United Kingdom \\ ${ }^{\mathrm{e}}$ Department of the Built Environment, School of Design, University of Greenwich, London, United \\ Kingdom \\ ${ }^{\mathrm{f}}$ Instituto de Ingeniería, Universidad Nacional Autónoma de México, 04510 Ciudad de México, México
}

\begin{abstract}
In Brazil, bioelectricity generation from sugarcane bagasse and black liquor is regarded as a sustainable electricity supply option. However, questions regarding land use, investment decisions, and demand for paper, ethanol and sugar make its future role uncertain. The aim of this paper is to present a novel modelling framework based on a soft-link between a multi-sectoral Brazilian integrated assessment model (MUSE-Brazil) and an electricity portfolio optimisation model (EPOM). The proposed framework is capable of dynamically simulating sectoral electricity demand, regional bioenergy production under land use constraints and optimal power sector technological shares in each of the electricity subsystems. Considering Brazil under a $2^{\circ} \mathrm{C}$ carbon budget, two scenarios based on economic attractiveness of producing second-generation ethanol have been investigated. Under the scenario where second-generation ethanol is not produced, outputs indicate that by 2050, Brazil would increase sugarcane and wood production by $68 \%$ and $49 \%$ respectively without causing direct or indirect deforestation. Agriculture intensification is evidenced as an alternative for reducing land use disruptions. Bioelectricity share is projected to remain around 9-10\%. However, if second generation ethanol becomes cost-effective, thus limiting bagasse availability, the share of bioelectricity production would decrease to approximately $7.7 \%$, with natural gas-fired plants playing a stronger role in the future power system expansion, causing an increase on electricity sector emissions.
\end{abstract}

Keywords: Brazil, bioenergy, electricity, land use, integrated models, optimisation

Word count: 8,782

\section{Introduction}

\subsection{Global bioenergy potential}

The current global utilisation of biomass for energy purposes is calculated to be around $50 \mathrm{EJ} \mathrm{y}^{-1}$ [1]. Bioenergy can be obtained from a wide range of sources such as agricultural and animal residues,

\footnotetext{
$=$ These authors contributed equally to this work

${ }^{1}$ Corresponding author

Email address: i.garcia-kerdan@imperial.ac.uk (Ivan Garcia Kerdan)
} 
forestry products and residues, municipal solid waste (MSW) and dedicated energy crops [2]. Commonly, the most affordable bioenergy feedstocks are MSW, followed by agricultural and animal residues, with dedicated energy crops regarded as the most expensive source [3]. While land use-related environmental impacts are a concern, biomass-based technologies have the potential to decarbonise the energy system.

Purkus et al. [4] examined the cost-benefit implications as well as uncertainties in bioenergy-oriented policy designs, with a focus on the UK and German programmes. The authors concluded that a careful and well-structured policy design, such as finding a balance between costs, taxes, incentives and policy adjustment instruments, is fundamental. Plevin et al. [5] concluded that emissions from indirect land use (iLUC) pose the greatest uncertainty in life cycle assessment (LCA) studies, where emissions could be far greater than previously calculated. Fazio and Monti [6] provided an LCA of different bioenergy production systems, including electricity generation from perennial crops. The outputs of the study suggest that bioelectricity based on perennial crops have a lower environmental impact than first generation $(1 \mathrm{G})$ biofuels and second generation $(2 \mathrm{G})$ bioethanol produced by thermo-chemical hydrolysis; on the other hand, biomass-to-liquid (BTL) biodiesel and 2G bioethanol through enzymatic hydrolysis were found to have lower environmental impacts. Kim and Dale [7] estimated the global annual bioethanol production potential from major agricultural crops, indicating that rice straw is the most favourable crop followed by wheat straw, corn, and sugarcane; yet, some of these benefits could come at an expense of reduced food and fibre production, posing a great risk to food prices and food security. Bryan et al. [8] investigated costs and benefits of a biofuel-oriented agriculture, showing that $1 \mathrm{G}$ biofuel has the potential of increasing renewable transport fuel use by becoming more economically profitable for producers. However, its greenhouse gas (GHG) abatement potential is rather minimal, especially when high vulnerability due to ecosystems perturbation from expected climate change and dryer conditions is considered.

As highlighted in Fazio and Monti [6], apart from biofuel production, one of the main biomass uses is in power generation. Direct combustion of agricultural residues or forestry products is the preferred choice due to its relatively low cost. González-García et al. [9] evaluated the environmental performance of ethanol and bioelectricity production systems using short rotation crops. The authors analysed two distinct scenarios: i) a biofuel scenario with $99.5 \%$ production of lignocellulosic bioethanol, and ii) bioelectricity scenario production through willow gasification in a biomass integrated gasification combined cycle (BIGCC) system. The LCA analysis demonstrated that the bioelectricity scenario has a greater potential for GHG emissions' abatement than the biofuel pathway.

As for bioelectricity, several researchers have considered its environmental impact compared to fossilbased power generation [10]. Faaij et al. [11] compared externalities from bioelectricity against coalbased power generation focusing on the environmental damage from the use of fertilisers and agrochemicals. Results suggest that apart from an adequate taxation of fossil-based power generation, dedicated energy crops should be limited to avoid uncontrolled expansion on arable land that could cause irreversible environmental damage. Njakou Djomo et al. [12] evaluated the GHG mitigation potential of short-rotation woody crops (SRWC), assuming an overall energy efficiency between 200$227 \%$, with a land demand of $0.9 \mathrm{~m}^{2} \mathrm{kWh}^{-1}$ for gasification and $1.1 \mathrm{~m}^{2} \mathrm{kWh}^{-1}$ if used for combustion. Up to $89 \%$ of the process life cycle emissions arose from land use change (food crops land into SRWC plantations); nevertheless, total emissions were still 50\% lower in relation to the average emissions from the EU non-renewable power mix (around $550 \mathrm{CO}_{2} \mathrm{kWh}^{-1}$ ). Boschiero et al. [13] studied differences in interpretation of agricultural residues with different allocation methods that eventually impact LCA. The authors used a full attribution LCA for wood residues-based combined heat and power (CHP) plants. Compared to conventional fossil-based systems, the authors concluded that emissions' allocation in the upstream process is the most sensitive parameter and has the largest influence in the final outputs. 


\subsection{Bioenergy and bioelectricity in Brazil}

Although Brazil is known for its high share of renewable energy for power generation, it still depends on energy obtained from fossil fuels. Also, due to higher growth rates in electricity demand in the last years, combined with dry seasons and depletion of water reservoirs, the power sector has increased its share of fossil fuels, mainly by installing more natural gas-based power generation. Non-renewable sources are also important to other activities, especially in the transport and industry sectors.

Brazil's power generation relies mainly on hydro resources (about 65-70\%), followed by biomass, natural gas and wind [14]. Wind power capacity has grown more than five-fold between January 2014 and December 2017 [15]. Although with high intermittence to offer electricity, its main contribution is to complement current hydro-based generation, avoiding shortages during drought periods. At present, decarbonisation of the power sector does not seem to be a pressing issue; however, as electricity demand is expected to increase at a rate of $3.7 \% \mathrm{y}^{-1}$ for the next decade [16], it will put more pressure to the current system, where hydro resources could become scarcer. As such, power generation from sustainable biomass could hold great potential for keeping a low-carbon power system.

Current bioenergy use, mainly from sugarcane, represents $16.9 \%$ of the domestic energy supply (2.1 EJ $\mathrm{y}^{-1}$ ) [14]. Approximately $67.3 \%$ of the sugarcane production comes from the Southeast of the country, with $57.3 \%$ only from the state of Sao Paulo [17]. With the increase of sugar and ethanol demands, sugarcane has expanded to other states and the Midwest region has become the new expansion area. In the last decade, land use patterns in this region have dramatically changed since the expansion of sugarcane and soybean plantations [18]. However, outside the most developed regions in Brazil (Southeast and South), information is still scarce on land use change caused by new bioenergy cultivations [19].

\subsubsection{Bioelectricity mix and regional distribution}

Due to availability of biomass residues, bioelectricity production has experienced fast growth rates in the last years. Bioelectricity represents the second biggest thermo-electricity source with similar installed capacities as natural gas power plants (around 14.5 GW) [20]. The two most important biomass resources are sugarcane (bagasse) and black liquor (waste obtained from pulpwood digestion), representing $76.8 \%$ and $17.5 \%$ of the installed capacity respectively (Figure 1). The Southeast and Midwest regions have the largest sugarcane-based installed capacity due to higher amounts of cane production, while black liquor-based generation is mainly present in regions with large pulp and paper industry, such as the Northeast and South regions. 


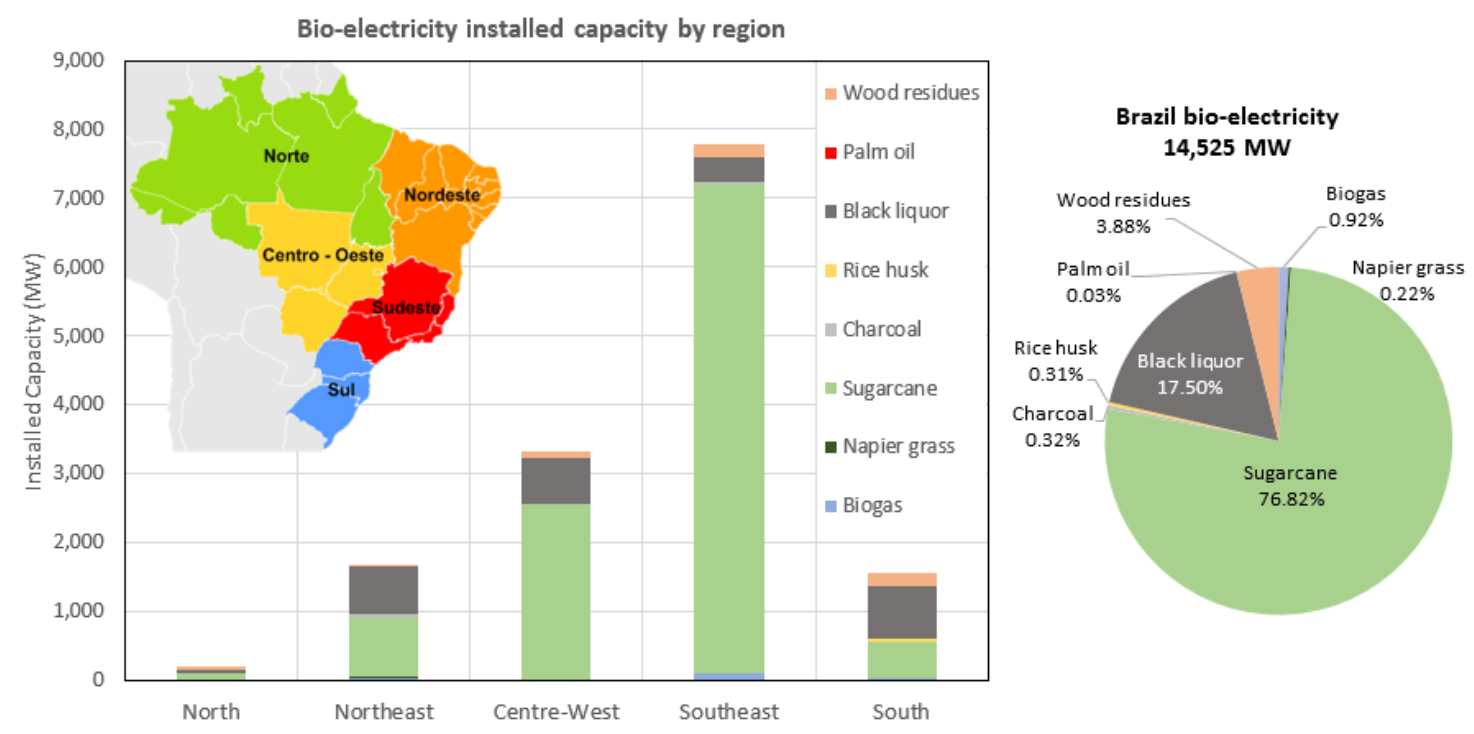

Figure 1 Bioelectricity installed capacity by source and by region (Source: ANEEL [20])

More information on bioelectricity generation technologies and historical production in Brazil can be found in Supplementary Information A.

\subsubsection{Sugarcane bagasse}

Several studies have investigated the use of sugarcane for bioelectricity generation in Brazil. Seabra and Macedo [21] performed a techno-economic and environmental analysis comparing electricity generation and ethanol production from sugarcane residues under two different ethanol-bioelectricity mill configurations: a) $91 \mathrm{~L} \mathrm{ton}^{-1}$ ethanol and $130 \mathrm{kWh} \mathrm{ton}^{-1}$ electricity (electricity option) and ii) 124 $\mathrm{L} \mathrm{ton}^{-1}$ ethanol and $50 \mathrm{kWh}$ ton $^{-1}$ electricity (ethanol option). The substitution of gasoline by ethanol led to greater environmental benefits than substitution of fossil-based power generation by bioelectricity; however, the former had lower economic advantage due to technological costs of $2 \mathrm{G}$ ethanol. Similarly, Dantas et al. [22] examined optimal mill configurations to produce ethanol and bioelectricity by performing cost analysis and projections for 2030. Findings show that current costs of $2 \mathrm{G}$ ethanol would limit its production, indicating electricity generation from biomass as the only economically feasible alternative for the following 15 years. Khatiwada et al. [23] estimated bioelectricity potential from Brazilian sugarcane bagasse at around $62-83 \mathrm{TWh}$. However, it is also feasible that $2 \mathrm{G}$ ethanol will become economically attractive in the future, thus limiting resource availability for bioelectricity production [24].

Moreira et al. [25] assessed the potential and cost-effectiveness of negative emissions of ethanol and bioelectricity production from sugarcane. The authors first considered biomass energy with carbon capture and storage (BECCS) at the fermentation stage, and later at the power generation stage. Using this plant design, outputs suggest that sugarcane mills could supply $77.3 \%$ of car fuel requirements and $17.9 \%$ of all electricity demand in Brazil but with a slight increase in prices for both ethanol and electricity. Grisi et al. [26] analysed the viability of generation rates proposed by the government using a mixed integer linear programming optimisation model aiming to achieve maximum profitability. The authors concluded that spot market prices were too low to encourage the sale of bioelectricity; however, oriented subsidies could promote it. 


\subsubsection{Black liquor}

Black liquor-based bioelectricity has been given less importance in research studies in Brazil compared to sugarcane bagasse; however, it is the most important biomass source in countries with considerable pulp and paper industries such as Sweden [27] and Finland [28]. For the Swedish case, Möllersten et al. [27] studied the emissions' reduction potential from the Swedish black liquor-based bioelectricity, finding emissions' reduction of up to $14 \%$ of national net emissions. If black liquor gasification technologies are coupled with CCS, the potential could increase to up to $26 \%$. Pettersson and Harvey [29] explored the utilisation of syngas from black liquor gasification in the production of electricity. Findings suggest that emission reductions highly depend on the pulp mill system configuration and biomass availability. Generation from syngas was considered favourable when the assumed electricity grid emissions were high.

\subsection{Research gap}

The mentioned studies contribute to a better understanding of the characteristics and relative advantages of biomass when compared to other energy sources. However, to the best of the authors' knowledge, there is still a lack of models that consider interactions between energy systems, power systems, bioenergy and land use, with the capability of optimising the supply-demand of regional bioenergy supply chains. Added to this, the identified studies usually considered large-scale regions (sometimes several countries grouped together), thus missing on regional socio-economic and ecosystems specificities that are important when evaluating energy systems. By considering these aspects and taking Brazil as a case study, the present study proposes a modelling framework to evaluate the availability and use of bioelectricity and their respective economic and environmental implications. Two scenarios are considered: 'Business as Usual' (BAU) scenario, where $2 \mathrm{G}$ ethanol production remains economically infeasible; and a pro- $2 \mathrm{G}$ ethanol scenario, where $2 \mathrm{G}$ ethanol production becomes costeffective and consumes part of the sugarcane bagasse to produce ethanol, which in turn reduces boilers biofuel availability and decreases bioelectricity generation potential. Moreover, direct and indirect land use changes are investigated under these scenarios.

Regarding the power sector, an optimisation model based on portfolio theory is applied to investigate the role of bioelectricity under two different economic policies: risk-taking and risk-averse. The model considers uncertainties in the transmission and generation costs of each electricity generation source and indicates the electricity mixes that provide the minimum expected cost, in the case of a risk-taking policy, and the minimum risk, in the case of a risk-averse policy.

The objective of this paper is twofold: i) describe a modelling framework that links the novel Brazilian multi-region/multi-sector Integrated Assessment Model (IAM), MUSE-Brazil, with an electricity portfolio optimisation model (EPOM), and ii) by using scenario analysis, investigate the maximum regional bioelectricity generation potential, considering dedicated expansion areas, as well as implications of $2 \mathrm{G}$ ethanol production in bioelectricity generation and land use demand.

This paper is organized as follows. First, a general overview of previous bioenergy and bioelectricity modelling efforts is presented. Following, the proposed modelling framework linking MUSE-Brazil and EPOM is presented. Next, to present the case study, Brazil's sugarcane and wood production projections alongside the proposed modelling scenarios are discussed. Then, the paper shows the results obtained for the selected case study, followed by discussions and conclusions. 


\section{Bioenergy modelling and its insertion in the power sector}

\subsection{Integrated Assessment Models (IAMs)}

Most evaluation efforts of bioenergy potential uses IAMs as these are key methodological tools for investigating long term trade-offs between energy system, land use, climate and the broader economic system [30]. Both general and partial equilibrium models have been developed enabling researchers to study how different systems interact and evolve over time under different scenarios. The literature on IAMs is now vast and has grown rapidly. The objective of these models is to project future climates with and without various types of climate change policies, aiming at stakeholders involved in deciding whether to implement various technologies or policies [31].

It is largely due to bioenergy research that ecosystems and land use have been linked to energy systems models [32]. Some IAMs that are used worldwide to forecast bioenergy uptake with a robust representation of the energy system are GCAM [32], TIMES [33], Balmorel [34], LEAP [35], POLES [36] and EnergyPLAN [37]. The most advanced IAMs that considers energy and agriculture modelling is GCAM [32]. The model can integrate the energy sector along natural ecosystems and terrestrial carbon cycles models, dividing the world into 151 agro-ecological regions.

Other comprehensive modelling efforts that consider the uptake of bioenergy and its implications in energy and environmental systems have been developed by several authors. Peter Witzke et al. [31] provided an exhaustive list of energy crop oriented agricultural models as well as different methodological frameworks applied in partial and general equilibrium models. McDonald et al. [38] analysed the macroeconomic impact of bioenergy (mainly switchgrass) as a substitute for crude oil in the USA by using a General Equilibrium Model. The authors investigated the impact of higher bioenergy production and its implications on world food and oil prices. White et al. [39] used an economic model to understand the joint response of the agriculture and forestry sectors when bioelectricity demand grows, mainly driven by an increase in national renewable shares. Biomass supply could be achieved with low impact on GHG land cycles, land use change, and prices. Nevertheless, the authors projected an increase in deforestation rates from agriculture and energy crops in response to higher demands for food and renewable energy.

Smeets et al. [40] evaluated bioenergy potentials up to the year 2050, focusing on dedicated energy crops, agricultural residues, and forestry products, with estimations of 215-1,272 EJ y ${ }^{-1}$. Haberl et al. [41] considers that upper values seem implausible mainly due to two methodological shortcomings: i) overestimation of area available to dedicated energy crops, that resulted from a lack of consideration of constraints, and ii) expectations of high yields due to errors in extrapolations. Therefore, a more plausible range is estimated to lie between $160-270 \mathrm{EJ} \mathrm{y}^{-1}$ when technical and environmental constraints are considered. Ricci and Selosse [42] used TIMES-FR optimisation model to assess the global and regional potential of bioelectricity with carbon capture and storage (CCS), showing a global biomass demand between 71-148 EJ by the year 2050. However, to better evaluate the role of biomass for power generation, other available electricity generation sources must be considered.

\subsection{Modern portfolio theory (MPT) models}

In order to help decision-makers to define adequate electricity matrices that meet future demand, generation expansion planning (GEP) models have been developed in the past decades [43]. Pérez Odeh et al. [44] used a portfolio optimisation model to deal with risk in the electricity sector. The planning of the future electricity matrices is usually based on medium and long-term forecasts. Therefore, different sources of uncertainties can be considered to minimise risks of negative outcomes, such as increase in electricity prices and undesirable environmental and social impacts. Among the existent GEP models, portfolio theory-based models offer tools for dealing with uncertainties [45]. 
Initially proposed by Markowitz [46], MPT was developed with the objective of finding investment portfolios that yield efficient relations between expected returns and their risks. Given a set of $N$ investment options, their expected returns $\overline{\boldsymbol{r}}=\left(\bar{r}_{1}, \bar{r}_{2}, \ldots, \bar{r}_{N}\right)^{\prime}$, a risk aversion parameter $\lambda \in(0,1)$, let $\boldsymbol{x}=\left(x_{1}, x_{2}, \ldots, x_{N}\right)^{\prime}$ represent the share of each investment option in the portfolio, and risk $(\boldsymbol{x})$ be the risk measure associated to each decision. The problem can be formulated as follows:

$$
\min _{x \in \mathbb{R}^{N}}\left(-(1-\lambda) \cdot \boldsymbol{x}^{\prime} \cdot \overline{\boldsymbol{r}}+\lambda \cdot \operatorname{risk}(\boldsymbol{x})\right)
$$

Subject to:

$$
\begin{gathered}
x \geq 0 \\
\sum_{i=1}^{N} x_{i}=1
\end{gathered}
$$

By solving the above optimisation problem for different values of $\lambda$ a set of solutions is obtained that yield efficient relations between the expected return and risk.

In the original MPT formulation Markowitz adopted variance as risk measure, however, other measures can also be adopted. Artzner et al. [47] presented a set of desirable properties for risk measures translation invariance, sub-additivity, positive homogeneity and monotonicity - and defined all measures satisfying these properties as coherent. Some variance drawbacks motivated the choice of other measures as it does not assess the occurrence of events located on the tails of probability distribution functions (PDFs); thus, it penalises both positive and negative deviations from the mean value. An alternative tail risk measure is the Conditional Value at Risk (CVaR) [48], defined as the expected loss value under the condition that the loss is above some fixed $\beta$-percentile (eq. (4)).

$$
\operatorname{CVaR}_{\beta}=E\left(\text { loss } \mid \text { loss } \geq \text { percentile }{ }_{\beta}\right)
$$

Pflug [49] proved that CVaR is a coherent risk measure. However, depending on the PDFs followed by the random parameters, adoption of $\mathrm{CVaR}$ as risk measure can result in an objective function with high analytical complexity, which is difficult to minimize. To simplify the problem, Rockafellar and Uryasev [48] proposed a CVaR approximation function and the use of Monte Carlo simulation to discretize the loss PDF. By using auxiliary variables, they solve the CVaR minimisation problem through linear programming techniques.

One of the first applications of MPT to energy related decisions was proposed by Bar-Lev and Katz [50] with the objective of choosing a mix of different fossil fuels. Although most of the portfolio optimisation models seek to minimize risk constrained to a minimum expected return, an alternative approach is to minimise risk constrained to a maximum expected cost [51]. The use of MPT to handle electricity planning problems was first proposed by Awerbuch and Berger [52] with the aim of finding efficient electricity matrices in the EU. The authors pointed to the importance of developing efficient generating portfolios instead of focusing on a single lowest cost alternative. 


\section{Modelling framework}

\subsection{MUSE-Brazil}

MUSE-Brazil is a partial equilibrium IAM that covers all the sectors in the Brazilian economy. While the majority of global IAMs are based on optimisation, MUSE-Brazil is based on a simulation framework aiming to realistically represent stakeholders' decision-making process for investment into new technologies. This approach brings engineering reality by characterising in detail different technologies across sectors. One of its main characteristics is the limited foresight approach that can be used in modelling future energy commodity prices [53]. More details of the model can be found in Supplementary Information B.

\subsubsection{Land use and land use constraints}

For this study, the regional land use model has been characterised based on different data sources. For agricultural, pasture and urban land, data has been gathered from the Instituto Brasileiro de Geografia e Estatística (IBGE) [54] and FAOSTAT [1]. Finally, sugarcane regional land has been collected from the União da Indústria de Cana-de-Açúcar (UNICA) [55]. To account for Brazilian forests and natural vegetation areas, as well as silviculture areas, data has been obtained from Ministério do Meio Ambiente (MME) [56]. A more detailed presentation of the Brazilian biomes' regional distribution and a summary of the baseline regional land use data are found in Supplementary Information B.

To understand regional land use differences, Figure 2 illustrates the share per land type in each region. Large amounts of forest and natural vegetation land in most of the regions, particularly in the North and Northeast are noticeable. Cropland and pasture are more predominant in the Midwest and Southeast, while silviculture is predominant in the Southeast and South.
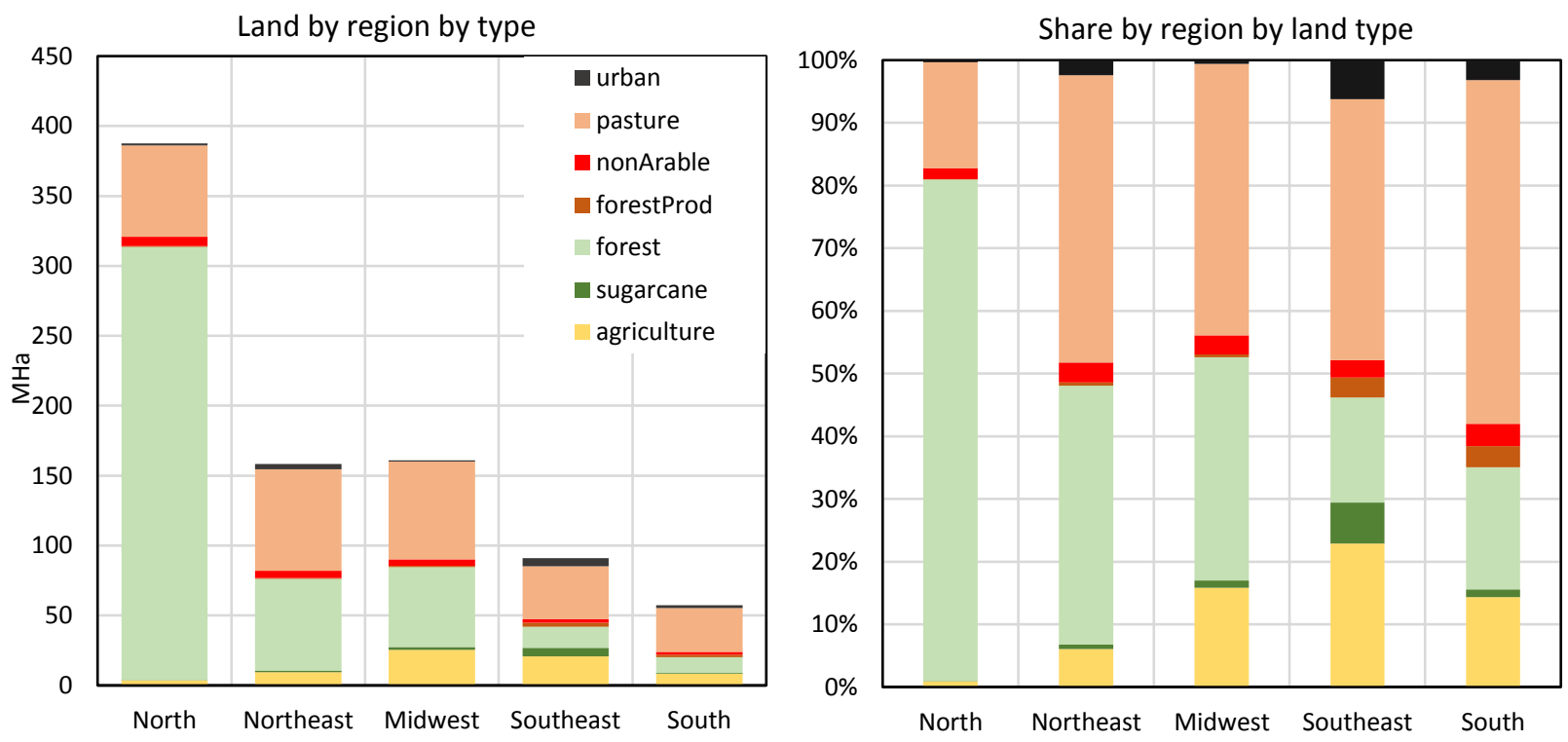

Figure 2 Land use demand and land use share by region

As land availability for sugarcane, wood and bioenergy production is not unlimited, constraints have been applied to reduce deforestation or indirect land use change caused by sugarcane or silviculture expansion. Potential available land data has been obtained from Ministério da Agricultura, Pecuária e Abastecimento (MAPA) published in the Zoneamento Agroecológico de Cana-de-Açúcar (ZAECana) [57]. According to the report, the agro-ecological zoning would make $92.5 \%$ of the Brazilian territory unsuitable for sugarcane production. Only around 65 Mha of agricultural land that is currently under production has been identified as suitable. The land use is distributed among pasture, crops and a 
mixture of both. The pasture and crops spatial distribution as well as the sugarcane expansion suitability levels are presented in Supplementary Information B. These levels depend on land's biophysical characteristics, meaning that different yields could be obtained if sugarcane expands into these areas. However, as MUSE-Brazil do not have an explicit spatial characterisation, if available land is taken by new sugarcane plantations, the model simulates process with average production yields. Productivity by region is discussed in Section 4.

Table 1 shows the amount of regional land that could potentially become available for sugarcane and silviculture. These values serve as constraints in the model. However, for agricultural land to become available, modern mechanisation and most efficient practices in crop and pasture production need to be implemented [58]. This is endogenously simulated in MUSE-Brazil, where demand for farm mechanisation emerges at the point when it becomes cost-effective in comparison with less productive processes. Depending on the amount of available former agricultural land in a period, the model would allocate, if necessary, new sugarcane and silviculture production processes and calculate the required investments to cover the surplus demand for sugarcane and wood products.

Table 1 Maximum suitable potential areas for sugarcane and silviculture expansion by type of former land use (values in Mha) (MAPA [57])

\begin{tabular}{lcccc}
\hline Region & Pasture & Agricultural & Agricultural + Pasture & Total \\
\hline North & 1.0 & 0.0 & 0.1 & 1.1 \\
Northeast & 1.8 & 1.0 & 2.4 & 5.2 \\
Midwest & 18.5 & 0.0 & 11.8 & 30.3 \\
Southeast & 13.7 & 0.6 & 8.4 & 22.7 \\
South & 2.2 & 1.6 & 1.9 & 5.7 \\
\hline Brazil & 37.2 & 3.2 & 24.6 & 65.0 \\
\hline
\end{tabular}

In the case where there is no former agricultural land available and a surplus of sugarcane or wood demand still exists, it is expected that available sugarcane and forestry product lands would increase productivity by increasing investments in mechanisation. Although it is assumed that sugarcane would not cause deforestation, the model assumes that typical agricultural crops or pasture could expand and remove natural forests.

\subsection{EPOM}

EPOM is based on Markowitz's Modern Portfolio Theory [46] used for finding compositions of electricity generation sources that result in efficient relations between expected cost and financial risk to meet electricity demands for specific points in time. EPOM is concerned with the expected value and Conditional Value at Risk of the sum of the levelized cost of electricity (LCOE) [59] and the transmission system tariff paid by the generators [60]. By grouping the Brazilian Midwest and Southeast regions, the model considers four interconnected electricity subsystems: i) North, ii) Northeast, iii) Southeast/Midwest and iv) South ${ }^{\dagger}$. Transmission and distribution losses that occur during the supply process are taken into account, as well as the environmental issues that constrain the installation of new power plants (e.g. local hydric resources, wind power potential and biomass availability), current existent power plants, different subsystems' demand levels and the need for having rapid ramp-up

\footnotetext{
† The state of Maranhão is in the Northeast political region but it belongs to the North electricity subsystem. Also, the states of Acre and Rondônia are in the North political region but belong to the Southeast/Midwest subsystem. EPOM considers that Maranhão is part of the North subsystem while Acre and Rondônia are part of the Southeast/Midwest subsystem.
} 
generating sources in the matrix. The model outputs are the regional amounts of electricity produced through biomass, wind, nuclear, oil, natural gas, coal, solar and hydropower plants.

Generation projects that are currently in operation or under construction, present investment costs that have already been incurred (sunk costs). Therefore, besides the generation potentials, EPOM also considers a minimum amount of regional generation for each source according to the existing power sector infrastructure [20]. Losses that occur during electricity exchanges between subsystems and local electricity distributions are also modelled [61]. Keeping high shares of intermittent sources diminishes demand attendance reliability, exposing the system to shortages during low generation and high demand periods. Therefore, to ensure supply security and realistic solutions, EPOM considers a minimum ratio between steady and intermittent sources. The model formulation is presented in the Supplementary Information C.

Economical inputs are covariances and expected values of operation and maintenance, investment, fuel and transmission costs $\left(\mathrm{R} \$ \mathrm{MWh}^{-1}\right)$ of each source in each subsystem [17]. To attract investments in renewables, the Brazilian government grants reductions of at least $50 \%$ on transmission tariffs paid by generators that produce electricity through wind, biomass, solar or small hydropower plants. These discounts are also considered in the model. Finally, as solar energy has presented important cost reductions during the last years, and based on the study by Elshurafa et al. [62], an 80\% learning curve for its cost is considered (see Supplementary Information C).

\subsection{MUSE-EPOM framework}

In this study, MUSE-Brazil has been soft-linked to EPOM. The simulation process starts by MUSEBrazil dynamically exchanging a set of variables with the MUSE Market Clearing Algorithm (MCA) by sending electricity demand, land use and emissions per region, time period and time slice. Then the MCA returns with a set of fuel and carbon prices. MUSE-Brazil provides the spatiotemporal aggregated electricity demand to EPOM as well as the amount of biomass potential.

The soft link leaves the two models separate where bioenergy supply functions are integrated into EPOM. Regional generation potentials of sources different than sugarcane bagasse, black liquor and coal, are based on different Brazilian government institutions' projections [63], renewable energy studies [64] and historical building rates data [65]. These are calculated in EPOM by applying the following equation:

$$
y_{i s}(t)=c_{i s}-a_{i s} e^{-k_{i s}(t-2020)}
$$

Where $y_{i s}(t)$ is the maximum generation potential of source $i$, in subsystem $s$, at year $t \geq 2020$; and the parameters $a_{i s}, c_{i s}$ and $k_{i s}$ are such that $y_{i s}(2020)$ and $\dot{y}_{i s}(2020)$ are respectively equal to the estimated generation capacity and its maximum expansion rate for source $i$, at subsystem $s$, in 2020; and $\lim _{t \rightarrow \infty} y_{i s}(t)$ equals the maximum available generation potential of source $i$, to be exploited in subsystem $s$. The estimated values are shown in the Supplementary Information D.

EPOM will then generate the power system portfolio as well as the share of bioelectricity production in the wider Brazilian power generation system at specific points in time (i.e. 2020, 2025, 2030, 2035, 2040, 2045 and 2050) for each of the Brazilian electricity subsystems. To account for infrastructure built with time, the generation constraints of bioelectricity, hydro, solar and wind for every planning milestone are adjusted such that their generation in a given time is lower or equal to their generation in subsequent times. Figure 3 illustrates the proposed framework. 


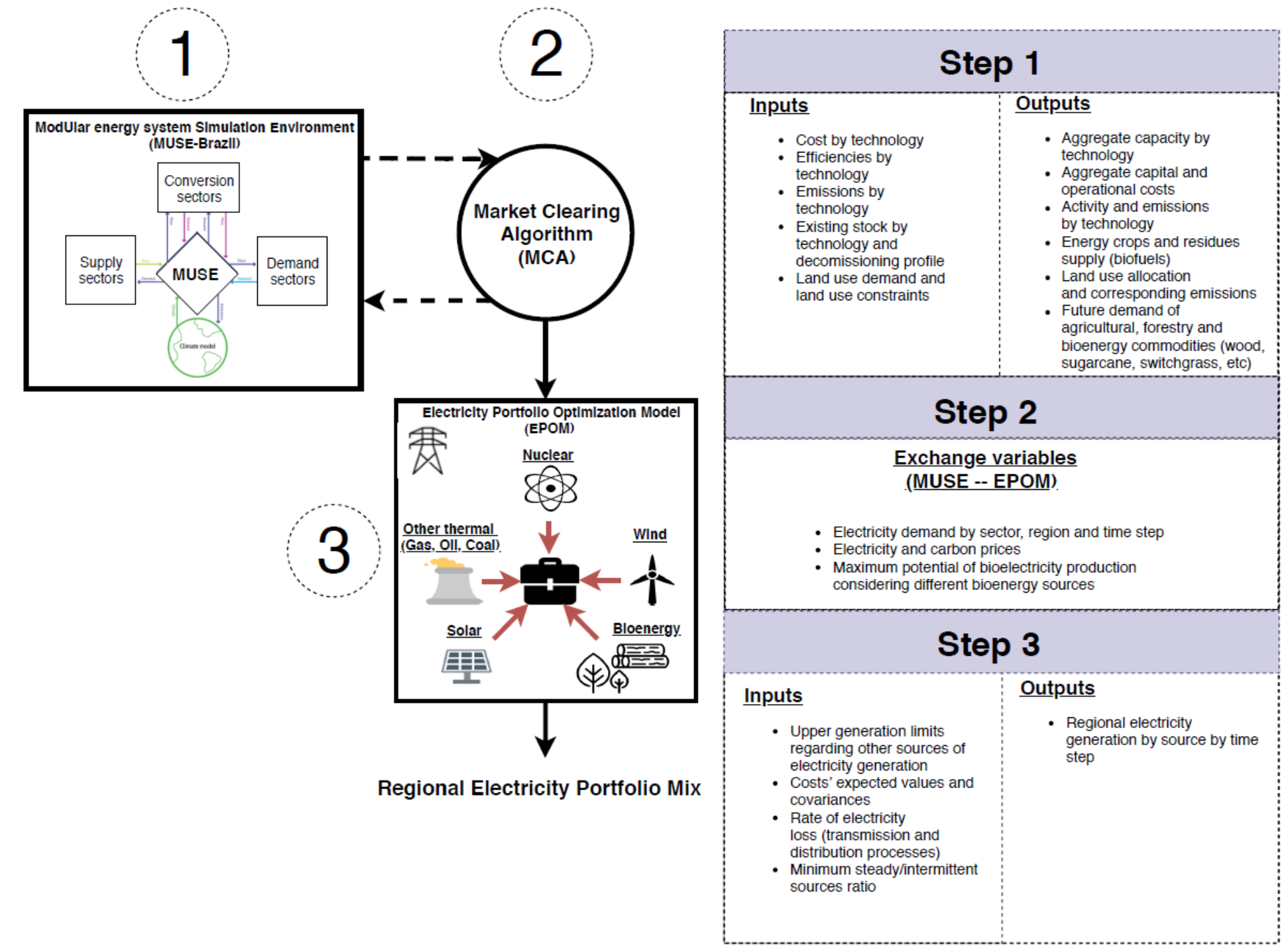

Figure 3 MUSE-Brazil - EPOM model integration and step by step simulation 


\section{Case study: Assumptions and future scenarios for bioenergy in Brazil}

\subsection{Sugarcane and black-liquor production forecast}

To obtain the future production of sugarcane and wood product, the model projects service demand for paper, sugar and ethanol. As shown in similar studies [66, 67], these demands have been derived from regression analysis defined with the help of macro-drivers such as gross domestic product (GDP) and population size. In this study, regional sugarcane and forest product demand projections are based on historical consumption trends [1]. The data has been obtained by UNICA [55] and IBGE [54] for the period 1960-2015. This data is correlated with regional GDP per capita and population data. Several regression models have been tested, with the following linearized function (log-log function) identified as the most appropriate to estimate demand for sugarcane products and paper:

$$
\ln (d(T))=a+b * \ln \left(G D P_{c a p}\right)
$$

Figure 4 illustrates the historical values and the obtained projections for sugarcane and pulp and paper respectively.
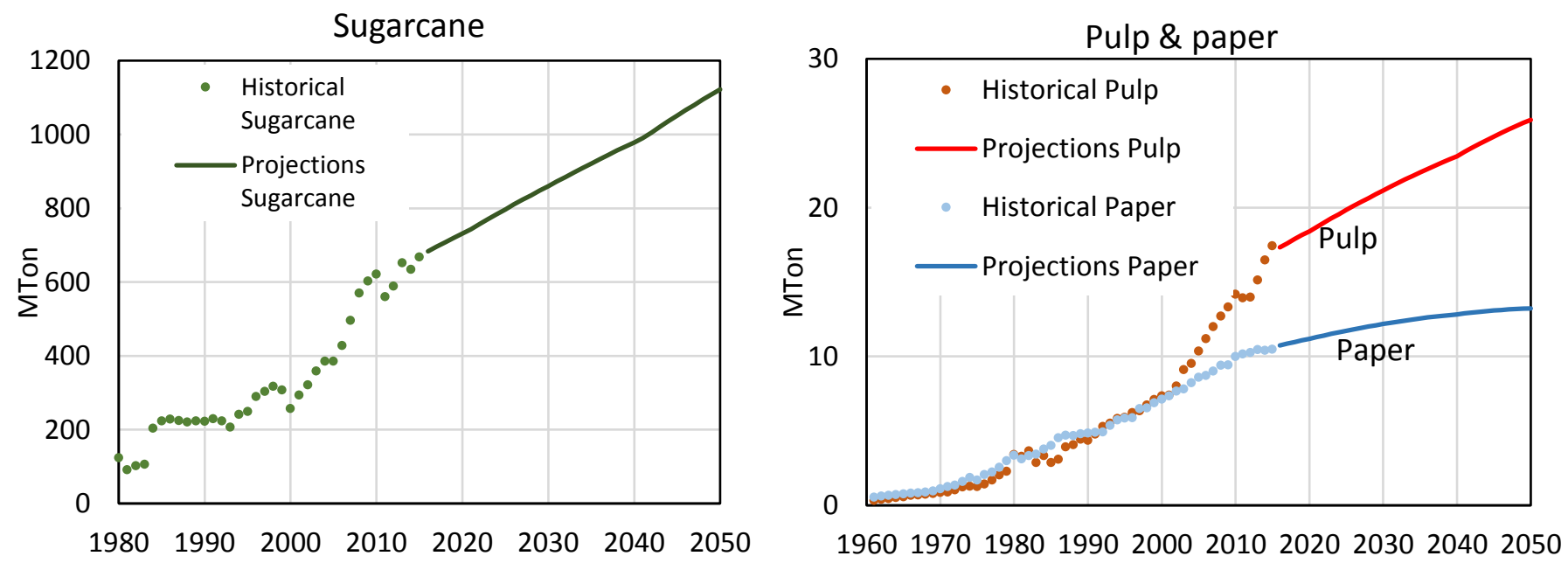

Figure 4 Historical and future projections of sugarcane and pulp and paper production

To model sugarcane production, data on current yields have been collected for municipalities from the five regions producing sugarcane [17]. Supplementary Information E presents the cumulative distribution of yields (ton ha ${ }^{-1}$ ) at a regional level. From the distributions, values to calibrate the MUSE agriculture and land use module [58] have been obtained. This was done by analysing production data and dedicated sugarcane area from UNICA [55]. Calibrated baseline values as well as the expected average productivity increase by the end of the simulation period (2050) are also presented in Supplementary Information E. It has been assumed that yields would increase within the current production rates, reaching maximum average values of 90 ton ha $^{-1}$ in the Southeast and minimum yields of 60 ton ha- in the North by 2050 .

For pulp and paper, the model would endogenously decide, based on technology's NPV, whether more efficient production processes would be installed in order to meet the required demand for wood products. Historically, growth in wood production has been around $4.7 \% \mathrm{y}^{-1}[54]$. 


\subsection{Scenarios}

End-use service demands projections for the rest of the sectors (buildings, industry, transport and agriculture) are based on IIASA's Shared Socioeconomic Pathways Two (SSP2) [68]. The SSP2 narrative describes a middle-of-the-road development in mitigation and adaptation and it has been used for both analysed scenarios. Based on these demands, MUSE-Brazil selects from different technological options in the different sectors, which would affect the final energy demand for electricity. Nevertheless, MUSE-Brazil has the capability to provide the demand for every energy commodity found in the energy system.

In this study, a $2^{\circ} \mathrm{C}$ carbon budget (2DS) has been considered for the analysed scenarios. Based on the study from Rochedo et al. [69], an average budget of $24 \mathrm{GtCO}_{2}$ from 2015 until 2050 for Brazil is considered. This budget considers both energy and land emissions, neglecting implications of agricultural emissions in achieving national mitigation targets.

Thus, two different 2DS scenarios have been defined to understand the potential of sugarcane bagasse and black liquor on the production of bioelectricity. The first scenario considers a business as usual bioenergy production approach (2DS+BAU), where sugarcane bagasse is mainly used for bioelectricity. It is assumed that during the milling process, $73 \%$ of sugarcane total mass is extracted for juice production [22]. Sugar and ethanol are then produced from the juice in proportions that will depend on both the refinery's processes design and on market conditions (prices). The remaining $27 \%$ of sugarcane mass turns into bagasse, which is assumed to be used in boilers to produce process steam and bioelectricity. The produced electricity can be used for either supplying the refinery's demand and/or to be negotiated in the electricity market for exporting to the national grid.

The second scenario assumes that $2 \mathrm{G}$ ethanol production becomes cost effective (2DS+2GE), which would consume part of the bagasse that was previously available for electricity generation. The considered conversion rates for producing each product are given in Table 2.

Table 2 Production parameters for sugarcane and pulp and paper industry

\begin{tabular}{|c|c|c|}
\hline Parameter & Value & Source \\
\hline \multicolumn{3}{|l|}{ Sugarcane } \\
\hline Litres of ethanol per ton of sugarcane $\left(\mathrm{L} \mathrm{ton}^{-1}\right)$ & 81.37 & USDA-FAS [70] \\
\hline Tons of sugar per ton of sugarcane (ton ton ${ }^{-1}$ ) & 0.1232 & USDA-FAS [70] \\
\hline Tons of bagasse per ton of sugarcane (ton ton $^{-1}$ ) & 0.27 & Corrêa Neto and Dan [71] \\
\hline Litres of $2 \mathrm{G}$ ethanol per ton of bagasse $\left(\mathrm{L} \mathrm{ton}^{-1}\right)$ & 149.3 & Walter and Ensinas [72] \\
\hline Bagasse heating value ( $\mathrm{MJ}$ ton $\left.^{-1}\right)$ & 7,536 & Carpio and Simone de Souza [24] \\
\hline Tons of lignin per ton of bagasse (ton ton ${ }^{-1}$ ) & 0.25 & Peng et al. [73] \\
\hline Lignin energy content $\left(\mathrm{MJ}\right.$ ton $\left.^{-1}\right)$ & 17,979 & Liu and Bao [74] \\
\hline Electricity per ton of sugarcane $\left(\mathrm{kWh}\right.$ ton $\left.^{-1}\right)$ & 150 & Khatiwada et al. [75] \\
\hline $\begin{array}{l}\text { Electricity generation efficiency with bagasse as } \\
\text { fuel }(\%)\end{array}$ & $26.5 \%$ & $\begin{array}{l}\text { Khatiwada et al. [75], Carpio and } \\
\text { Simone de Souza [24] Corrêa Neto } \\
\text { and Dan [71] }\end{array}$ \\
\hline \multicolumn{3}{|l|}{ Pulp and paper } \\
\hline Tons of black liquor per ton of pulp (ton ton ${ }^{-1}$ ) & 1.7 & IEA-Bioenergy [76] \\
\hline Black liquor heating value $\left(\mathrm{MJ}\right.$ ton $\left.^{-1}\right)$ & 12,300 & Naqvi et al. [77] \\
\hline $\begin{array}{l}\text { Electricity generation efficiency with black liquor } \\
\text { as fuel (\%) }\end{array}$ & $13.0 \%$ & IIP [78] \\
\hline
\end{tabular}


Based on these parameters, production of ethanol, sugar, and electricity per ton of crushed sugarcane as well as electricity per ton of pulp production can be estimated for each scenario. Figure 5 shows a simplified scheme while Table 3 presents the estimated production parameters for both scenarios.

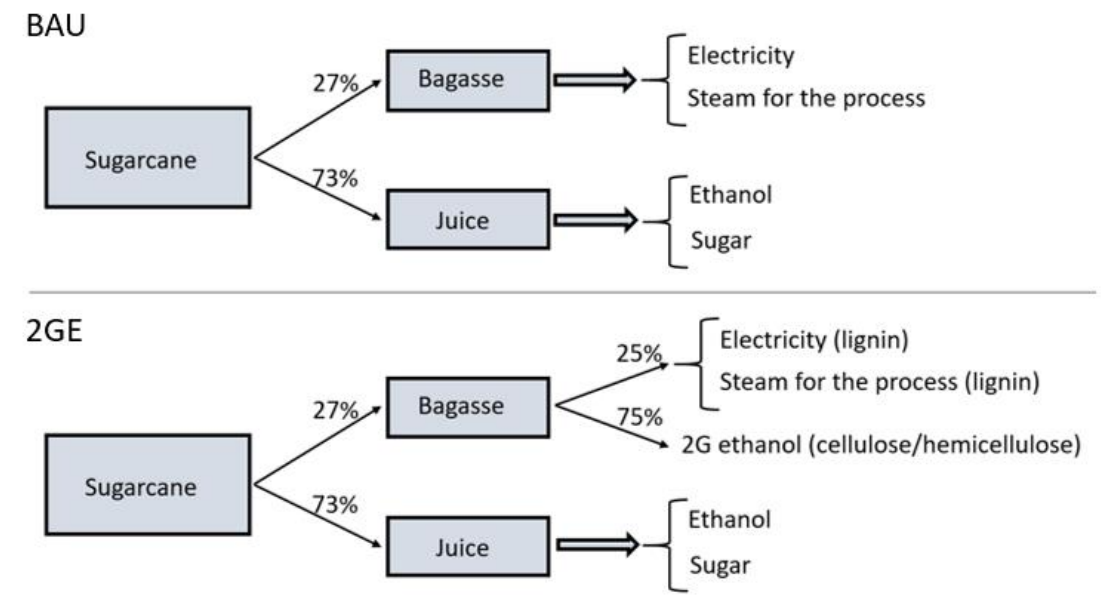

Figure 5 Sugarcane production and its residues mass share for BAU and 2GE scenarios

Table 3 Sugar, ethanol and electricity yields

\begin{tabular}{|c|c|c|}
\hline Scenario & Product & Yield \\
\hline \multirow{4}{*}{ 2DS+BAU } & Sugar & 0.1232 (ton ton ${ }^{-1}$ of sugarcane) \\
\hline & Ethanol & 81.37 (liters ton $^{-1}$ of sugarcane) \\
\hline & Electricity from sugarcane & 0.150 (MWh ton ${ }^{-1}$ of sugarcane) \\
\hline & Electricity from pulp & 0.75 (MWh ton ${ }^{-1}$ of pulp) \\
\hline \multirow{4}{*}{$2 \mathrm{DS}+2 \mathrm{GE}$} & Sugar & 0.1232 (ton ton ${ }^{-1}$ of sugarcane) \\
\hline & Ethanol & 121.68 (liters ton $^{-1}$ of sugarcane) \\
\hline & Electricity from sugarcane & 0.089 (MWh ton ${ }^{-1}$ of sugarcane) \\
\hline & Electricity from pulp & 0.75 (MWh ton ${ }^{-1}$ of pulp) \\
\hline
\end{tabular}

\section{Results and discussion}

\subsection{Electricity demand}

Considering the 2DS carbon budget in both scenarios, similar cross-sectoral electricity demand has been obtained. Figure 6 shows future electricity demand by region and by sector. Modelling outputs suggest that electricity demand would grow $85.0 \%$ between 2015 and 2050, reaching $989 \mathrm{TWh} \mathrm{y}^{-1}$. Regionally, it is the Southeast that would experience the highest rise, increasing $236.2 \mathrm{TWh} \mathrm{y}^{-1}$ by 2050 . This represents $52.0 \%$ of the total national new power demand. Its share among regions would slightly increase from $50.0 \%$ to $50.9 \%$. Also, high demand growth rates in the North and Northeast are expected, going from 107.8 to $231.0 \mathrm{TWh} \mathrm{y}^{-1}$ by 2050 , increasing its combined national demand share from $20.2 \%$ to $23.4 \%$. The South region would increase demand by $51.4 \mathrm{TWh} \mathrm{y}^{-1}$, while the Midwest would increase by $43.4 \mathrm{TWh}^{-1}$. The model foresees that national electricity per capita consumption would increase from 2.60 to $4.25 \mathrm{MWh} \mathrm{cap}^{-1}$. According to the IEA [79], this value is similar to current consumption rates in Poland $\left(4.1 \mathrm{MWh} \mathrm{cap}^{-1}\right)$, Chile $\left(4.2 \mathrm{MWh} \mathrm{cap}^{-1}\right)$, Hungary $\left(4.2 \mathrm{MWh} \mathrm{cap}^{-1}\right)$ and China (4.3 MWh cap $\left.{ }^{-1}\right)$. 

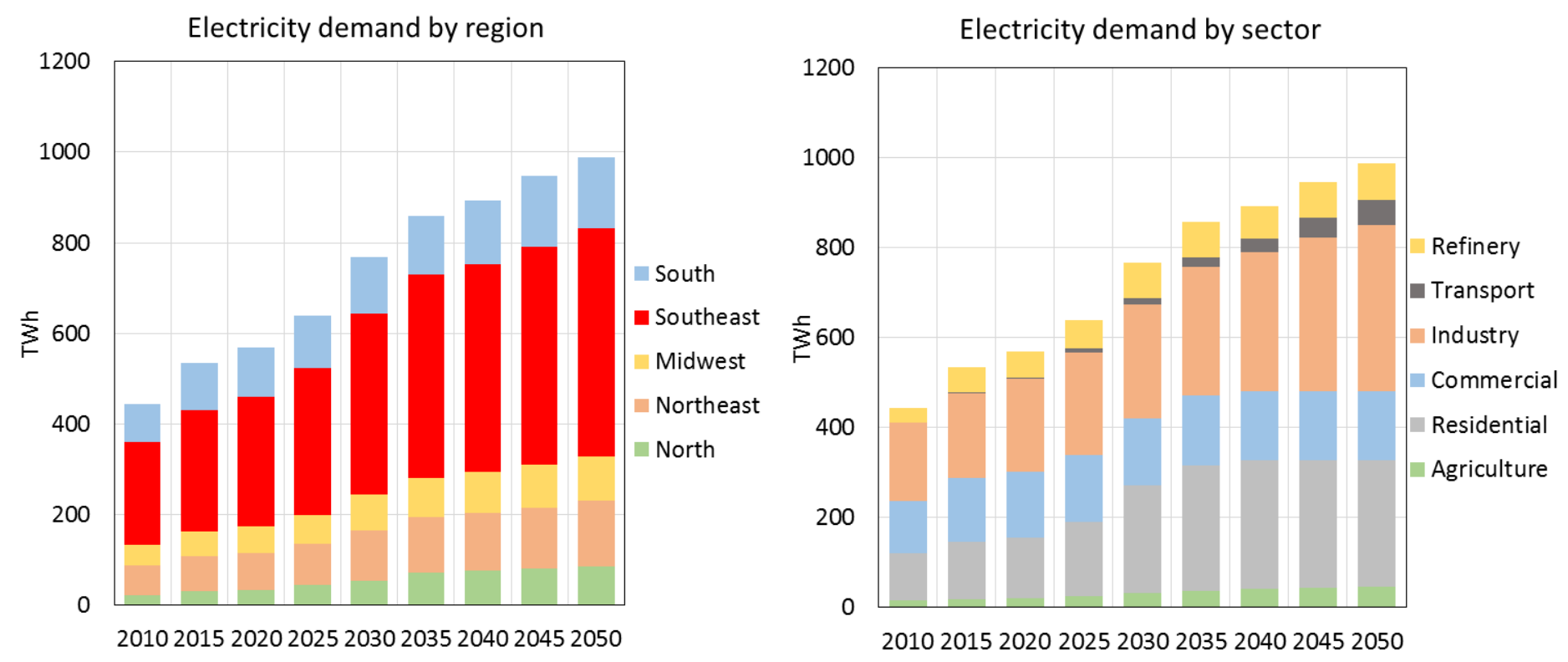

Figure 6 Electricity demand projections by region (left) and by sector (right) in Brazil

As for the sectors, the industrial sector would have the highest absolute increase, from $189 \mathrm{TWh} \mathrm{y}^{-1}$ in 2015 to $369 \mathrm{TWh} \mathrm{y}^{-1}$ in $2050\left(+180.4 \mathrm{TWh} \mathrm{y}^{-1}\right)$. This would be followed by the residential sector, reaching $282 \mathrm{TWh} \mathrm{y}^{-1}$ by $2050\left(+153.7 \mathrm{TWh} \mathrm{y}^{-1}\right)$. Transport sector would increase from a current demand of 3 to $55 \mathrm{TWh} \mathrm{y}^{-1}\left(+52.4 \mathrm{TWh} \mathrm{y}^{-1}\right)$, followed by refinery $\left(+27.7 \mathrm{TWh} \mathrm{y}^{-1}\right)$ agriculture $(+27.6$ $\left.\mathrm{TWh}^{-1}\right)$ and commercial $\left(+12.3 \mathrm{TWh}^{-1}\right)$ sectors. Regional electricity demand values separated by sector are given in Supplementary Information F.

\subsubsection{Sectoral electricity demand and technology uptake outlook}

\section{a. Agriculture}

MUSE simulates technological uptake based on mechanisation or intensification levels. Overall, the uptake of modern technologies result in the increase in energy and agrochemicals while reducing land use. In this study, the model shows that the Southeast and Northeast regions would experience the highest increase in electricity demand driven by mechanisation adoption, thus improving production efficiency in pasture and crop lands. Both regions combined would increase demand by $26.3 \mathrm{TWh} \mathrm{y}^{-1}$, representing $95.2 \%$ of the total national demand increase in the sector. Specifically, the Northeast is the region that would experience the highest rate of mechanisation adoption due to a higher increase in economic activity and an increase in agricultural products demand, closing the gap between regions. Also, the North region would experience growth in agricultural production, with higher rates of new installed agricultural production capacity $\left(0.8 \mathrm{TWh}^{-1}\right)$. On the other hand, slower mechanisation uptake is expected in the Midwest and South, increasing electricity demand by a combined value of 0.4 TWh $\mathrm{y}^{-1}$. Mostly, this is due to lower economic dynamism as the South region already possess high mechanisation levels. More detailed information can be found in [58].

\section{b. Residential}

The Southeast and Northeast would experience the largest electricity demand growth, increasing by 64.5 and $31.0 \mathrm{TWh} \mathrm{y}^{-1}$ respectively. This represents $62.1 \%$ of the national sectoral increase. Electric boilers covering domestic hot water and electric ovens for cooking would drive most of new demand; however, for the first 25 years, unitary air conditioners (AC) to cover cooling demand would cause the highest increase. By 2040, the model expects the cooling demand to be covered by both air-source and ground-source heat pumps, minimising electricity demand per cooling service unit.

\section{c. Commercial}


Overall, the commercial and public sector would experience the lowest demand increase. Although an increase in service demand is expected, only the North and Northeast regions would experience above average growth rates. It is predicted that the national sectoral demand would plateau close to 2050 due to the uptake of efficiency measures in the Southeast region. As a whole, the sector currently demands $141 \mathrm{TWh} \mathrm{y}^{-1}$, reaching a maximum demand of $156 \mathrm{TWh} \mathrm{y}^{-1}$ by 2035, to later reduce to $154 \mathrm{TWh} \mathrm{y}^{-1}$ by 2050. Currently, the Southeast is responsible for $72.8 \mathrm{TWh} \mathrm{y}^{-1}$ of the total sectoral demand $(51.5 \%)$; this is expected to reach $74.9 \mathrm{TWh} \mathrm{y}^{-1}$ by 2050 . The sector improvement in efficiency is a result of widespread installation of heat pumps and LED lighting. Heat pumps (mainly GSHP) would be responsible for three quarters of the cooling demand, while LED lights would be responsible for $89.6 \%$ of the lighting installed capacity.

\section{d. Industry}

Nationally, $30.5 \%$ of the energy demand in the industry would be covered by electricity, followed by biomass (sugarcane bagasse and wood) and coal. Total power demand would grow from $189 \mathrm{TWh} \mathrm{y}^{-1}$ in 2015 to $369 \mathrm{TWh} \mathrm{y}^{-1}$ in 2050. Most of the industry electrification is expected to occur in the Southeast, specifically in the pig \& iron and cement industries. The region would be responsible for about $57.3 \%$ or $103.3 \mathrm{TWh} \mathrm{y}^{-1}$ of new electricity demand, while the other four regions combined would be responsible for a demand increase up to $77.1 \mathrm{TWh}^{-1}$. Other industries that would experience high demand growth rates are pulp and paper industry (both mechanical and chemical pulping processes) in Northeast and South regions, and ethylene and nitrogen fertilizers' production in the Northeast and Southeast respectively.

\section{e. Transport}

Transport electrification would increase the sectoral electric demand by $52.4 \mathrm{TWh} \mathrm{y}^{-1}$. Although most of the heavy transport would still rely on diesel, electric cars (including plug-in hybrids) would represent $62 \%$ of the total road passenger demand, decreasing the share of flex fuel cars to only $18.8 \%$. Electricbased transport capacity would be distributed as follows: the Southeast would have the largest share (56.8\%) due to its higher income and population number, followed by the South and Northeast (each about $14.6 \%)$, Midwest (11.4\%), and North (2.6\%).

\section{f. Refinery}

Electricity demand in the sector would grow from 55.2 to $82.9 \mathrm{TWh} \mathrm{y}^{-1}$ by 2050 . Although most of the refinery capacity would remain in the Southeast, the model also projects new refinery capacity in the Northeast and South. These three regions combined would be responsible for $26.2 \mathrm{TWh} \mathrm{y}^{-1}$ or $94.4 \%$ of the increase in electricity demand. Over the first years, oil refineries are expected to expand mainly in the Northeast while bio-refineries in the Midwest. Other bio-refineries that would increase production are biogas upgrade, biodiesel production from transesterification and BTL through gasification, steam reforming and Fischer Tropsch thermo-chemical processes.

\subsection{Land use demand and biomass production}

Figure 7 illustrates the national land use demand in the simulated period for both scenarios. The model estimates that under the 2DS+BAU scenario, agricultural land demand (crops, pasture, bioenergy and silviculture) would peak by 2020, reaching $292 \mathrm{Mha}$ (an increase of $3.5 \%$ ). Then, due to investments in agricultural modern technologies, mainly in pasture production, the sector is expected to liberate the land at a rate of $0.7 \%$ annually, occupying 230 Mha by 2050 . This means that around 68 Mha of land or $8.0 \%$ of the total Brazilian territory could be available for natural vegetation regeneration. For the 2DS+2GE case, due to lower energy crop production, total agricultural land would occupy 225 Mha by 2050, having liberated 72.9 Mha. 

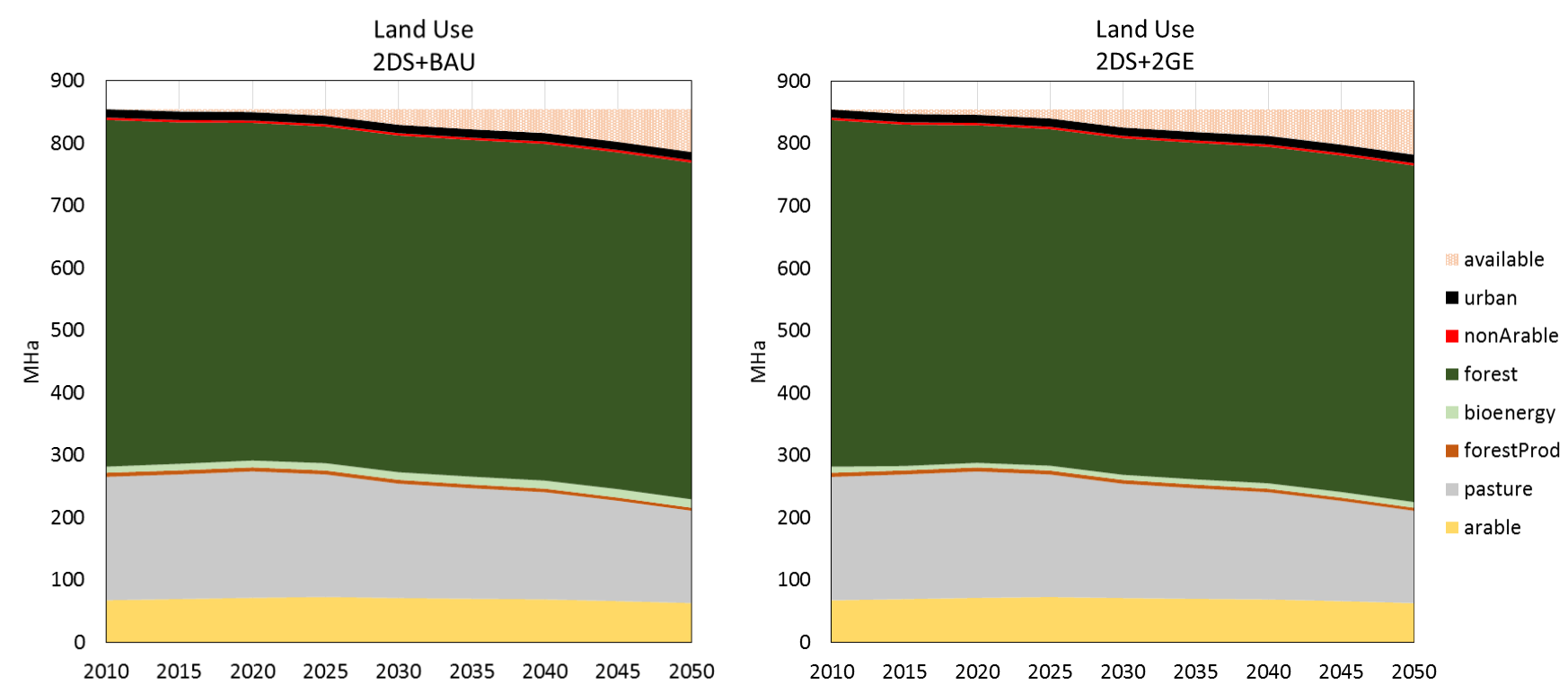

Figure 7 Projected national land use demand by type for 2DS+BAU and 2DS+2GE scenarios

In the case of sugarcane and silviculture, in the 2DS+BAU scenario, the model considers that by 2050,

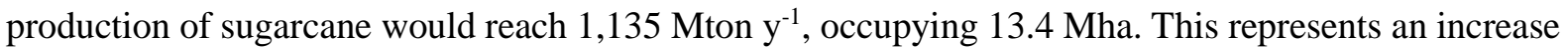
of 3.7 Mha, mainly taken from former pasture land. From this, 2.5 Mha would come from the Southeast, 0.9 Mha from the Midwest, 0.2 Mha from the South, 0.1 Mha from the Northeast and 0.02 Mha from the North. Although sugarcane land would expand by $29.2 \%$ compared to 2015 , it is expected that production would increment by $66.2 \%$, meaning that the sector will improve productivity from an average value of 65.7 ton $\mathrm{ha}^{-1}$ in 2015 to 84.4 ton $\mathrm{ha}^{-1}$ by 2050 . As the model restricts production of new sugarcane plantations only to abandoned lands, and due to the absence of abandoned land by 2020 , the model forces the increase in productivity in the current sugarcane plantations for the first simulation period. If these restrictions were not assumed, new sugarcane plantations would require 0.48 Mha of natural forest land, mainly in the Midwest region (Cerrado biome). In the 2DS+2GE scenario, as $2 \mathrm{G}$

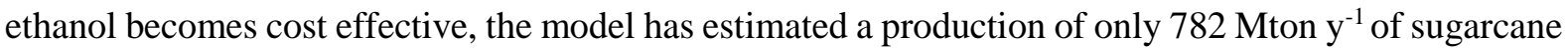
required to cover both sugar and ethanol demands. This represents $68.9 \%$ of the sugarcane production necessary in the 2DS+BAU scenario. In this case, demand for sugarcane land would be reduced to 9.0 Mha. On the other hand, wood demand for paper production would reach about $13.3 \mathrm{PJ} \mathrm{y}^{-1}$ in wood content (an increase of $49 \%$ compared to 2015), producing $25.9 \mathrm{Mton}^{-1}$ of pulp. The land use model suggests that for both scenarios, forestry would occupy 4.9 Mha by 2050, after reaching a peak land demand of 6.5 Mha in 2020. By the end of the simulated period, the South and Southeast would be responsible for $71 \%$ of the pulp and paper industry, followed by the Northeast (12\%) and Midwest $(12 \%)$.

Overall, it is expected that the Southeast and Midwest regions would liberate land at higher rates by 2050, reaching a combined total of 36.5 Mha for 2DS+BAU and 40.2 Mha for 2DS+2GE. Forest and natural vegetation land, originally composed by $555 \mathrm{Mha}$ in the base year, would be reduced to around 540 Mha by 2050 for both scenarios. Most of the deforestation would occur during the first 15 years (2010-2025), with the Midwest (mostly in the Cerrado biome) responsible for 85\% or 13 Mha of forest removal. This deforestation is caused by cropland expansion, mainly driven by new sugarcane, soybean and maize crops.

Nevertheless, for both scenarios, thanks due to agriculture intensification, the model has projected minimum disruptions in the North region (Figure 8). This region is important as it holds 305.4 Mha or 89.4\% of the Amazon forest. Tropical forests, such as the Amazon, are considered important carbon sinks for carbon dioxide sequestration from the atmosphere. Although deforestation rates in the Amazon have decreased threefold compared to the last decade, 0.8 Mha were removed from the biome in 2016 [80]. At this rate, by 2050 a forest area corresponding to the size of Italy would be removed. Thus, controlling deforestation in the Amazon, either through technological improvement or policy controls, 
would be fundamental for Brazil to reach its carbon mitigation targets. Moreover, the model has projected that an additional 13.97 and 13.99 Mha of previous agricultural land for 2DS+BAU and 2DS+2GE respectively, could be available for reforestation, increasing the regional carbon sequestration potential. Similarly to previous studies [81], outputs from this study show the wider importance of pasture intensification for reducing GHG emissions through both livestock management and land use management. Land use demand for the rest of the regions for both scenarios can be found in the Supplementary Information G.
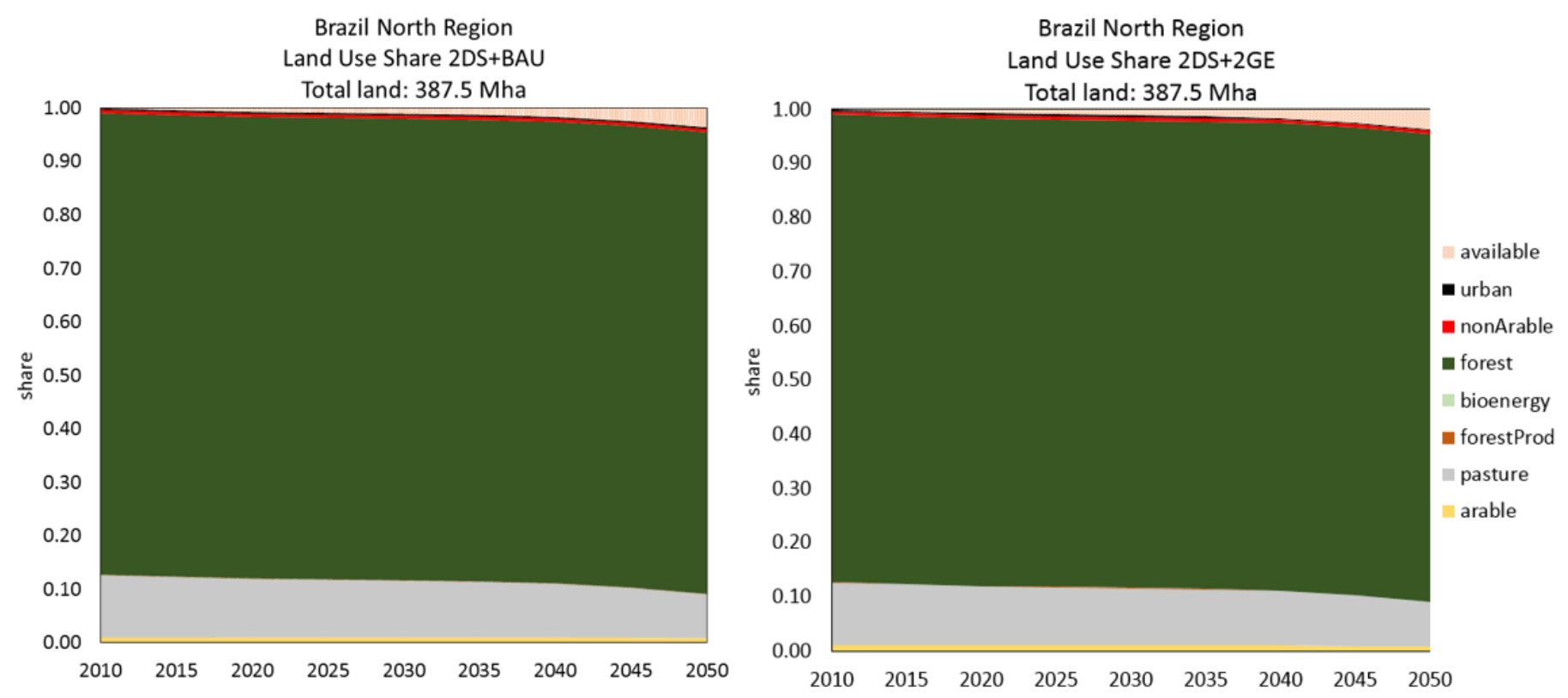

Figure 8 North region land use demand forecast for 2DS+BAU and 2DS+2GE scenarios

\subsection{Electricity generation}

As illustrated in the proposed framework, regional electricity demand and maximum biomass resources have been sent to EPOM. For each scenario, Figure 9 shows the upper bounds for bioelectricity generation in each period. The Brazilian bioelectricity potential is considerably reduced when there is production of $2 \mathrm{G}$ ethanol, which would consume part of the sugarcane bagasse that could be used for electricity production. This also shows the importance that decision-making and development of the sugarcane industry have on the country's bioelectricity production.

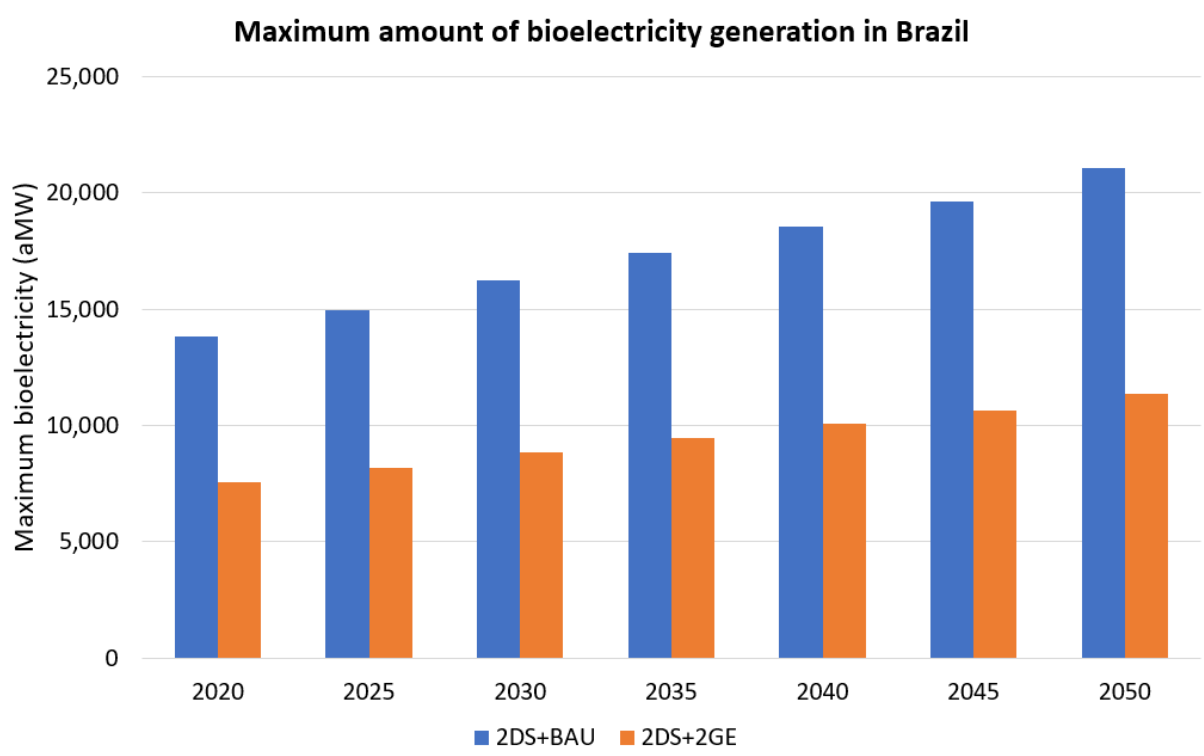

Figure 9 Brazilian bioelectricity potential for each scenario 


\subsubsection{Electricity generation per source}

To further investigate possible impacts in the power sector, outputs from EPOM regarding electricity generation are shown for both scenarios and for risk taking and risk averse policies, where risk aversion parameters are respectively $\lambda_{0}=10^{-10}$ and $\lambda_{1}=1-10^{-10}$.

Figure 10 shows that despite the considered scenario or risk aversion parameter, expansion of the Brazilian matrix is given mainly through renewables, mostly new hydropower plants and wind farms. The main difference, when varying the risk aversion parameter, is the interchange between hydroelectricity and wind power. For instance, when comparing the Brazilian generation mix in 2050 with regards to the risk policies, it is observed that in the risk averse case generation through wind is 34.45 TWh higher, whilst generation through hydro is $35.51 \mathrm{TWh}$ lower. Therefore, if a government is to develop a more conservative policy in terms of generation and transmission costs, it should stimulate the uptake of wind power. However, as in this case, if the portfolio theory is applied to deal with the trade-off between the expected cost and cost risk, such policy would result in an electricity matrix with higher expected cost.

Despite risk aversion, the main difference when considering the 2DS+BAU and 2DS+2GE scenarios is that in the 2DS+BAU there is more bioelectricity generation, while the use of natural gas is lower. Bioelectricity generation in 2050 is $15.0 \mathrm{TWh}$ higher in the 2DS+BAU, while generation through natural gas is $14.7 \mathrm{TWh}$ lower. Therefore, biomass availability can contribute to reducing the amount of fossil fuels in the power sector.

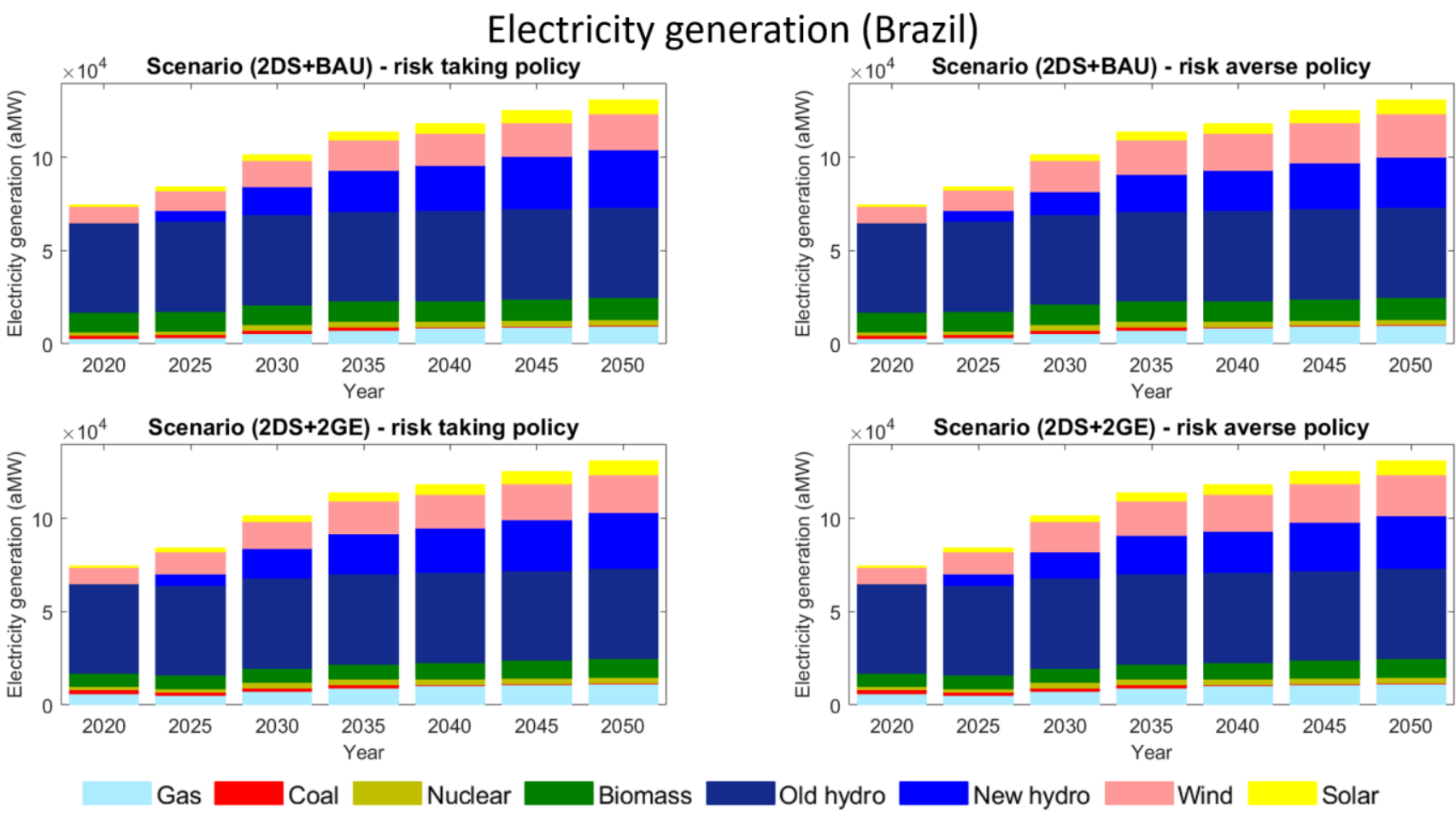

Figure 10 Brazilian electricity generation by source for 2020, 2025, 2030, 2035, 2040, 2045 and 2050

Electricity generation per source and by time-period in each subsystem is shown in Supplementary Information $\mathrm{H}$. With respect to generation in the North subsystem, an increase between the years of 2020 and 2035 is observed, which is the period where demand grows faster. The capacity expansion in the North enables exportation to the Southeast/Midwest subsystem.

The results for the Northeast are in line with the current trend of wind and solar power expansion. It is seen that expansion in this region also follows the growth in demand. Favourable conditions for building wind farms contribute to the region's capacity to achieve an amount of generation enough for both local 
consumption and exportation to the Southeast/Midwest subsystem. The growth of wind power in the region varies between 11.7 TWh (2DS+BAU risk-taking policy scenario) and 46.2 TWh (2DS+BAU risk-averse policy scenario) by 2050 . Since the Northeast is the region that most suffers from droughts, the increase in wind generation positively contributes to reducing its dependence on hydropower. Also, to mitigate hydropower shortfall risks, it presents the highest share of generation through thermo-power plants, with most of them being natural gas power.

Among thermal sources in the Southeast/Midwest, biomass-fired power plants present the highest share. This result reflects the strong presence of sugarcane industry in the region. Bioelectricity generation from sugarcane in the Southeast/Midwest is estimated to achieve 61.9 TWh for the 2DS+BAU scenario and 60.2 TWh for the 2DS+2GE scenario by 2050. Additionally, as a consequence of large biomass availability and high hydropower installed capacity, this region has higher shares of renewables compared to the North and Northeast subsystems. Unlike the Northeast, wind farms in the Southeast contribute to a small share of energy generation. In the $2 \mathrm{DS}+2 \mathrm{GE}$ scenario, natural gas power plants generation is intensified, whereas part of the natural gas is substituted by bioelectricity in the 2DS+BAU scenario. Higher rates for growth demand result in a constant increase in the local power generation. As for the other subsystems, the increase in demand comes mainly from the expansion of renewable sources. Nuclear generation will grow in 2030 , reflecting the fact that a new nuclear powerplant, which has been built in the state of Rio de Janeiro, is predicted to start operating in 2026.

Due to more regular hydrological regimes, the South subsystem presents the lowest electricity generation ratio between thermopower sources (gas, coal, oil and biomass) and renewable sources (hydro, wind, solar). Similar to the Northeast, favourable wind conditions makes power generation through this source important in the region. This characteristic, combined with lower electricity demand compared to other subsystems, as well as high hydropower installed capacity, makes this subsystem an electricity exporter.

Overall, when bioelectricity potential is reduced, natural gas has an augmented participation in the electricity portfolio. This result supports the Brazilian government's efforts to exploit the recent discovered natural gas reserves in the pre-salt layer. It also points out that if new and more cost-effective technologies to extract natural gas are developed, it could have a more important role for the future Brazilian power sector. It is observed that in the case of no $2 \mathrm{G}$ ethanol production (2DS+BAU), the share of bioelectricity generation in the power system would remain around 9-10\% in 2050. However, if $2 \mathrm{G}$ becomes cost-effective, it would be reduced to about $7.7 \%$.

To evaluate whether limited regional generation potential of different sources have an impact on the electricity mix, saturated generation potentials in each subsystem and year were evaluated for both riskaverse and risk-taking policies (see Supplementary Information $\mathrm{H}$ ). Some sources in the Southeast/Midwest and South subsystems that achieve their maximum generation potential when $2 \mathrm{G}$ ethanol is produced will not achieve it if $2 \mathrm{G}$ ethanol remains economically unattractive. This is the case for biomass and coal in the Southeast/Midwest. It is an important result since it indicates that larger biomass availability could reduce power generation through coal, which is one of the most polluting power generation sources.

\subsubsection{Electricity trade between regions}

Since Brazilian electricity subsystems are interconnected, the possibility of electricity exchanges can influence the amount of electricity generation in each region. It is important to note that due to geographical constraints there is no possibility of direct exchange between the South and North, and between the South and Northeast subsystems. Figures 11 and 12 show the EPOM's electricity exchange outputs for both scenarios. 

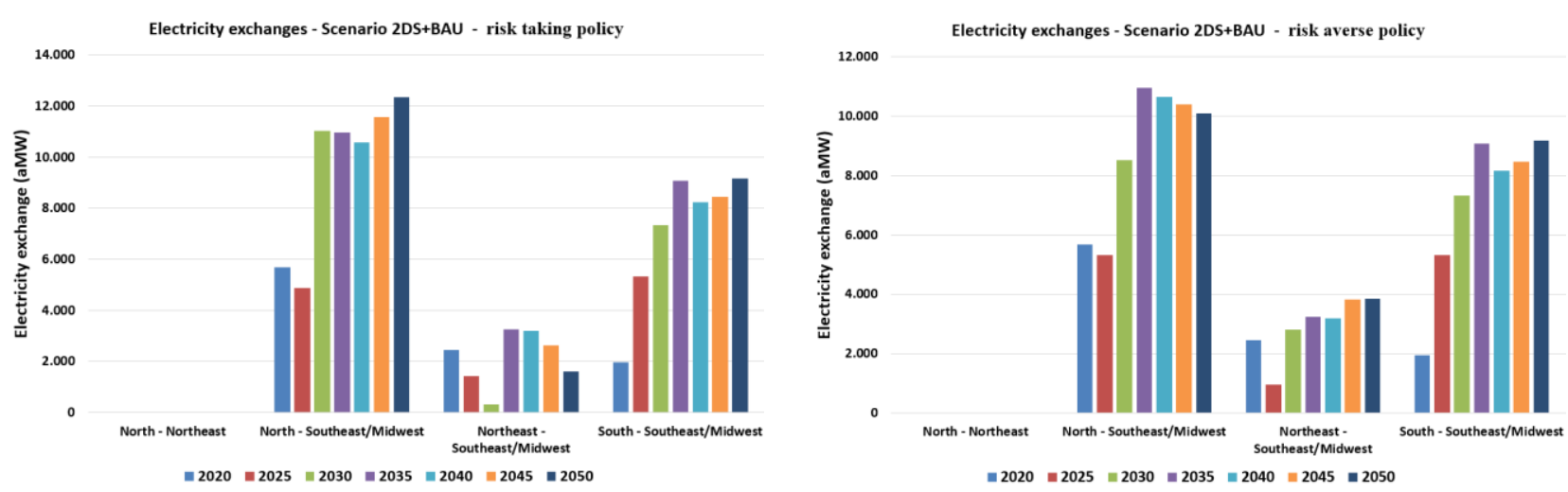

Figure 11 Electricity exchange for the Scenario 2DS+BAU. Left: Risk taking policy. Right: Risk averse policy
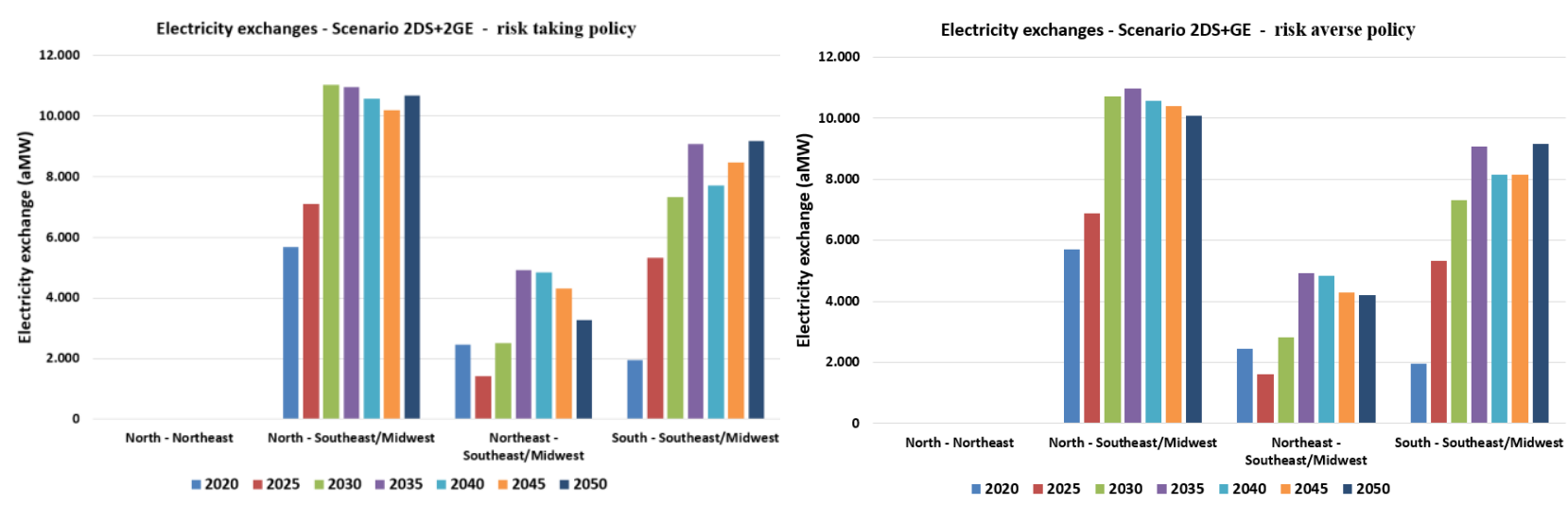

Figure 12 Electricity exchange for the Scenario 2DS+2GE. Left: Risk taking policy. Right: Risk averse policy

Results show that the North, Northeast and South subsystems export electricity to the Southeast/Midwest in every period for all scenarios and for both risk aversion parameters. This happens because the Southeast/Midwest electricity consumption is the highest compared to other subsystems, corresponding to about $60.4 \%$ of the national consumption in 2020 and accounting for $61.4 \%$ of the national consumption growth by 2050. Moreover, the uptake of wind and solar power in the North and Northeast subsystems contribute for their electricity surplus, which enables exportation.

\subsubsection{Emissions from power sector}

Power system's carbon emissions for each scenario are shown in Figure 13. The system with the lowest emissions is represented by the risk averse BAU approach 2DS+BAU $\left(\lambda_{1}\right)$. In this system, wind dominates $(+12 \%)$ compared to the risk-taking BAU scenario 2DS+BAU $\left(\lambda_{0}\right)$, where new hydroelectricity production is preferred $(+13 \%)$. Accumulated carbon emissions throughout the simulated period were found at $3.20 \mathrm{GtCO}_{2}$ for $2 \mathrm{DS}+\mathrm{BAU}\left(\lambda_{1}\right)$, while for $2 \mathrm{DS}+\mathrm{BAU}\left(\lambda_{0}\right)$ this was found at $3.23 \mathrm{GtCO}_{2}$. On the other hand, the $2 \mathrm{DS}+2 \mathrm{GE}$ scenarios presented higher emissions. Due to lower availability of biomass residues, $2 \mathrm{DS}+2 \mathrm{GE}$ scenarios have larger thermal-based electricity generation by natural gas $(+23 \%)$ and coal $(+12 \%)$. The accumulated carbon emissions were found at $3.48 \mathrm{GtCO}_{2}$ for $2 \mathrm{DS}+2 \mathrm{GE}\left(\lambda_{0}\right)$ and $3.46 \mathrm{GtCO}_{2}$ for $2 \mathrm{DS}+2 \mathrm{GE}\left(\lambda_{1}\right)$. Considering all scenarios, power system emissions could represent between $13.3 \%$ and $14.5 \%$ of the defined $2^{\circ} \mathrm{C}$ carbon budget for Brazil. 


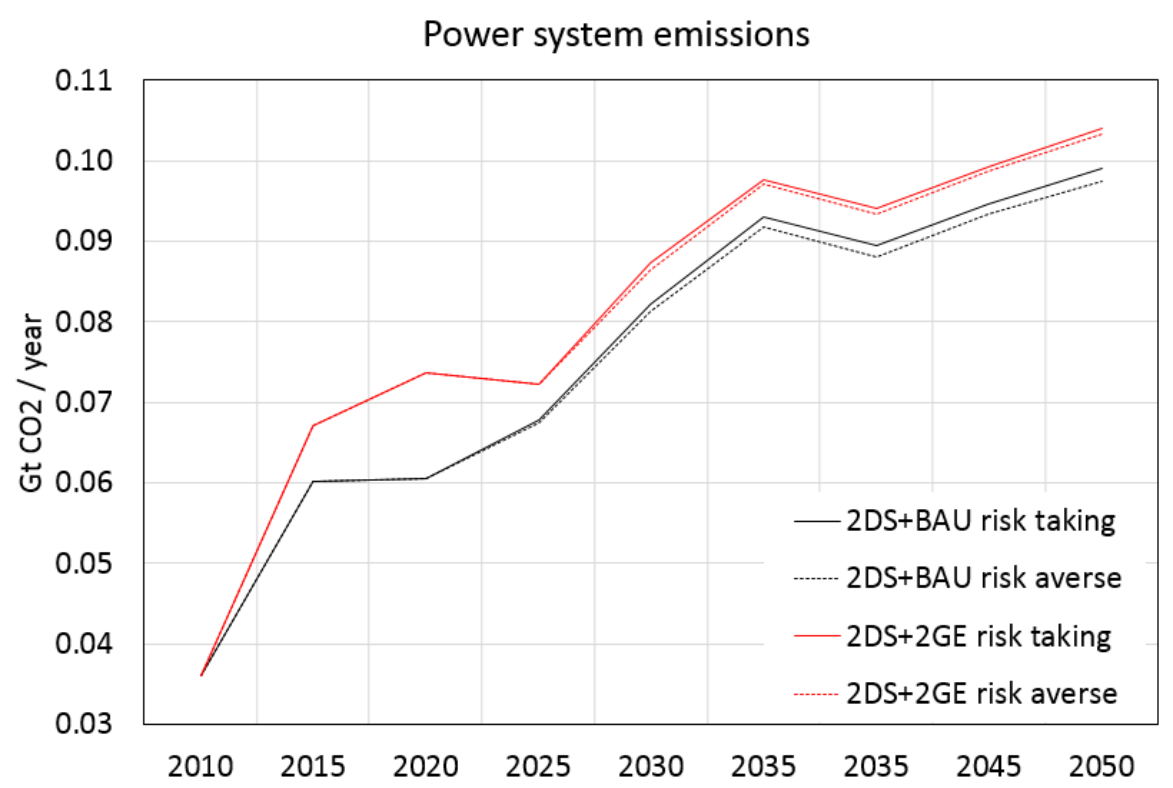

Figure 13 Brazil's power system emissions. Emission factors taken from Barros et al. [82]

\subsection{Practical implications of this study}

The prevalence of hydroelectricity in the Brazilian electricity system, the current saturation of adequate areas for new hydro power plants, and the expectation of electricity demand growth raise the challenge of diversifying the country's electricity matrix. In this case, biomass-based electricity production, considered as carbon-neutral generation source, could help maintain the clean credentials of the Brazilian power system. However, uncertainties such as the implications of indirect land use and land management are still a major concern. Thus, sustainable biomass or agricultural residues, which do not cause any direct or indirect land use change should be widely promoted.

Regarding the economic dimension, the attractiveness of bioelectricity is evidenced through the preference of its use against other thermopower technologies based on fossil fuels. This supports the current bioenergy policy, Renovabio [83], established in Brazil in 2017 with the aim to promote the expansion of biofuels in the energy sector. Moreover, reductions of bagasse availability for electricity generation in the $2 \mathrm{DS}+2 \mathrm{GE}$ scenario indicate that promoting other biomass sources than sugarcane is essential to guarantee higher bioelectricity expansion in the power sector.

Wind and solar power expansion in the North and Northeast can provide these regions with electricity surplus that could potentially be exported to other regions. Therefore, the proposed modelling framework can support decisions regarding the expansion of the transmission system. It is important to note that further analysis on the required transmission infrastructure to enable electricity exchanges was considered beyond the scope of this work.

Suggestions and recommendations for the future work that could enhance the analysis presented in this work are as follows: (i) detailed investigation of the future use of other biomass sources than sugarcane and black-liquor (e.g. palm oil, wood residues, rice husk, charcoal, napier grass and biogas); (ii) consideration of other specificities from the agricultural sector such as crop rotation dynamics and uncertainties on cattle intensification levels; (iii) explicitly modelling of the transmission system to improve estimations of costs and benefits from expanding exchange capacities; (iv) adoption of different risk measures in the portfolio optimization model. 


\section{Conclusions}

This study presented a novel modelling framework combining a simulation-based multi-regional energy system model with a power system portfolio optimisation model. The integrated framework has the capability to assess the future role of bioelectricity in a systems' context and its implications for an optimal power sector planning. The focus of this paper was to explore the potential of sustainable bioelectricity expansion in Brazil by studying the potential spread of the two major bioelectricity sources: bagasse from sugarcane and black liquor from the pulp process. The increase in production has been constrained only to abandoned agricultural lands in different regions. One of the main contributions from the proposed integrated framework is the capability to deal with the uncertainties due to land use, land use change emissions and energy-related technological routes, which directly affects the selection of the portfolio investment in the power system.

The model showed that improvements in sugarcane and wood production processes would increase bioelectricity production by 2050 . In the 'Business as Usual' scenario, while sugarcane production is expected to increase by $66 \%$, land demand would only increase by $29 \%$ or 3.7 Mha. This results from improvements in sugarcane productivity, increasing average national yields from 65.7 to 84.4 ton $\mathrm{ha}^{-1}$. If second-generation ethanol scenario is followed, lower sugarcane production would be required, reducing land requirements by 1.1 Mha. Results also suggest that for both scenarios, new required sugarcane area will expand at different rates in different regions, mostly on former pasture lands in the Southeast and Midwest regions, located mainly in the Mata Atlântica and Cerrado biomes. A similar phenomenon is expected in wood production for the pulp and paper industry. As the model projects agricultural mechanisation improvement and pasture intensification, land abandonment of former agricultural land is expected at about 22 Mha by 2030 and up to 49 Mha by 2050 . However, it is still expected that some agricultural crops would expand, causing deforestation of about 13 Mha. This would be mostly located in the Midwest region, specifically in the Cerrado biome.

For both scenarios, the Southeast/Midwest electricity subsystem presents the highest bioelectricity potential as well as the highest average potential growth rate. The Business as Usual scenario indicates that Brazil has the potential to maintain its current bioelectricity share of about $10 \%$ until 2050, where sustainable biomass feedstocks would have the capacity to produce up to $92 \mathrm{TWh} \mathrm{y}^{-1}$ of electricity in 2020 and up to $104 \mathrm{TWh} \mathrm{y}^{-1}$ in 2050 . On the other hand, if the surplus bagasse is mainly used for $2 \mathrm{G}$ ethanol, the share of bioelectricity production would decrease to about $7.7 \%$ in 2050 , reducing production levels to $60 \mathrm{TWh} \mathrm{y}^{-1}$ in 2020 and $89 \mathrm{TWh} \mathrm{y}^{-1}$ in 2050. Such reductions would result in the increase of electricity generation from fossil fuels. Among available technologies, natural gas-based power generation has experienced a steady growth due to cost-effectiveness and reliability. Additionally, recently discovered gas resources in the pre-salt layer could make the gas option attractive. However, subsequent increase in emissions in Brazil's power sector would make it more difficult for the country to achieve its national reduction targets and transition to a low-carbon economy.

\section{Acknowledgements}

This work was supported by the Natural Environment Research Council (NERC) with grant number NE/N018656/1; Fundação de Amparo à Pesquisa do Estado de São Paulo (FAPESP) with grant numbers 2015/50684-9 and 2017/50136-7; Coordenação de Aperfeiçoamento de Pessoal de Nível Superior Brasil (CAPES) with finance code 001; and Brazilian National Research Council (CNPq) with grant numbers 306734/2014-1 and 307126/2018-8. 


\section{Nomenclature}

\section{Sets}

Set of subsystems:

S $\quad$ North, Northeast, Southeast/Midwest, South $\}$

Set of generation technologies:

$T \quad$ \{natural gas, oil, coal, biomass, wind, new hydro, old hydro, new nuclear, old nuclear, solar $\}$

\section{Parameters}

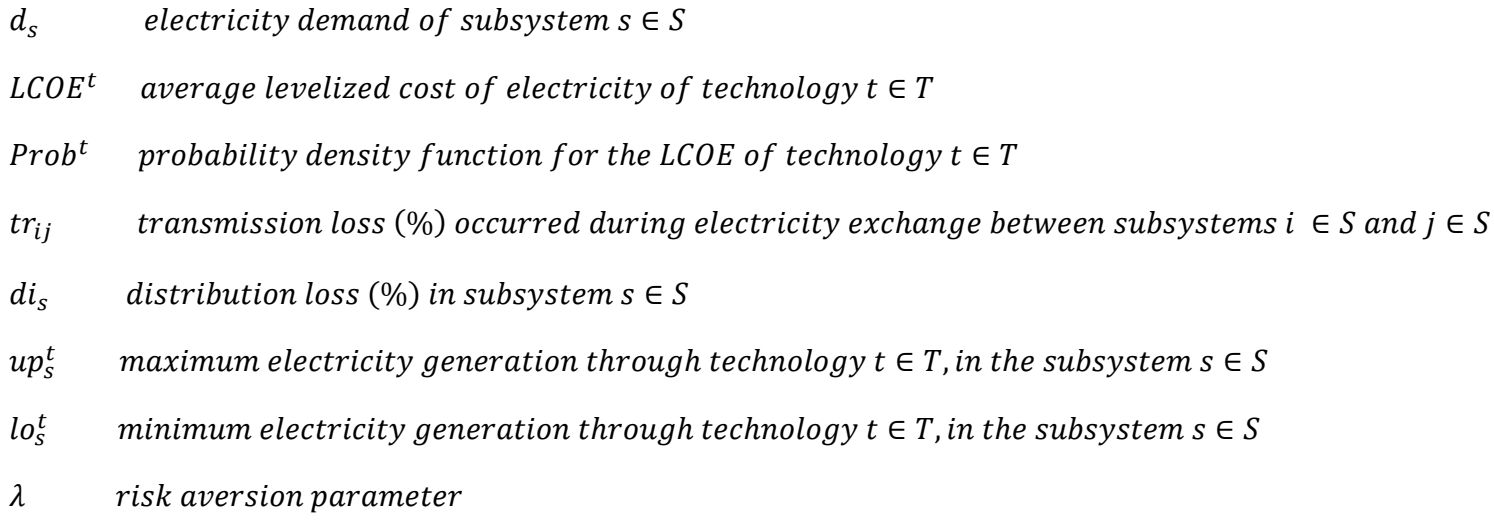

Decision variables

$x_{i j}^{k} \quad$ amount of generation in the subsystem $i \in S$, through technology $t \in T$, to be sent to subsystem $j \in S$

\section{References}

[1] FAO. FAOSTAT. In: http://www.fao.org/faostat/en/\#data, editor.2017.

[2] Raphael Slade, Robert Saunders, Robert Gross, Bauen A. Energy from biomass: the size of the global resource. London, UK: Imperial College Centre for Energy Policy and Technology and UK Energy Research Centre; 2011.

[3] Sanchez DL, Nelson JH, Johnston J, Mileva A, Kammen DM. Biomass enables the transition to a carbon-negative power system across western North America. Nature Clim Change. 2015;5:230-4.

[4] Purkus A, Röder M, Gawel E, Thrän D, Thornley P. Handling uncertainty in bioenergy policy design - A case study analysis of UK and German bioelectricity policy instruments. Biomass and Bioenergy. 2015;79:64-79.

[5] Plevin RJ, O'Hare M, Jones AD, Torn MS, Gibbs HK. Greenhouse Gas Emissions from Biofuels' Indirect Land Use Change Are Uncertain but May Be Much Greater than Previously Estimated. Environmental Science \& Technology. 2010;44:8015-21.

[6] Fazio S, Monti A. Life cycle assessment of different bioenergy production systems including perennial and annual crops. Biomass and Bioenergy. 2011;35:4868-78.

[7] Kim S, Dale BE. Global potential bioethanol production from wasted crops and crop residues. Biomass and Bioenergy. 2004;26:361-75.

[8] Bryan BA, King D, Wang E. Biofuels agriculture: landscape-scale trade-offs between fuel, economics, carbon, energy, food, and fiber. GCB Bioenergy. 2010;2:330-45. 
[9] González-García S, Iribarren D, Susmozas A, Dufour J, Murphy RJ. Life cycle assessment of two alternative bioenergy systems involving Salix spp. biomass: Bioethanol production and power generation. Applied Energy. 2012;95:111-22.

[10] Sebastián F, Royo J, Gómez M. Cofiring versus biomass-fired power plants: GHG (Greenhouse Gases) emissions savings comparison by means of LCA (Life Cycle Assessment) methodology. Energy. 2011;36:2029-37.

[11] Faaij A, Meuleman B, Turkenburg W, van Wijk A, Ausilio B, Rosillo-Calle F, et al. Externalities of biomass based electricity production compared with power generation from coal in the Netherlands. Biomass and Bioenergy. 1998;14:125-47.

[12] Njakou Djomo S, El Kasmioui O, De Groote T, Broeckx LS, Verlinden MS, Berhongaray $\mathrm{G}$, et al. Energy and climate benefits of bioelectricity from low-input short rotation woody crops on agricultural land over a two-year rotation. Applied Energy. 2013;111:862-70.

[13] Boschiero M, Kelderer M, Schmitt AO, Andreotti C, Zerbe S. Influence of agricultural residues interpretation and allocation procedures on the environmental performance of bioelectricity production - A case study on woodchips from apple orchards. Applied Energy. 2015;147:235-45.

[14] EPE. National Energy Balance 2016 (Balanço Energético Nacional 2016). In: Energética EdP, editor. Rio de Janeiro, Brazil Ministry of Mines and Energy (Ministerio de Minas e Energia ); 2017.

[15] ONS. Operador Nacional do Sistema Eletrico (National Electrical System Operator) Acervo digital. In: http://ons.org.br/pt/paginas/conhecimento/acervo-digital/documentos-epublicacoes, editor. Brazil 2018.

[16] EPE. Ten Year Energy Expansion Plan 2026 (Plano Decenal de Expansão de Energia 2026). In: Energética EdP, editor. Rio de Janeiro, Brazil Ministry of Mines and Energy (Ministerio de Minas e Energia); 2017. p. 264.

[17] IBGE. Produção Agrícola Municipal (Food \& Beverage Municipal Production), Sistema IBGE de Recuperação Automática - SIDRA. In: https://sidra.ibge.gov.br/pesquisa/pam/tabelas, editor. Brazil 2018.

[18] Rathmann R, Szklo A, Schaeffer R. Land use competition for production of food and liquid biofuels: An analysis of the arguments in the current debate. Renewable Energy. 2010;35:14-22.

[19] Spera S, VanWey L, Mustard J. The drivers of sugarcane expansion in Goiás, Brazil. Land Use Policy. 2017;66:111-9.

[20] ANEEL. Capacidade de Geração do Brasil (Brazil's Generation Capacity). In: http://www2.aneel.gov.br/aplicacoes/capacidadebrasil/capacidadebrasil.cfm, editor. Brazil 2018.

[21] Seabra JEA, Macedo IC. Comparative analysis for power generation and ethanol production from sugarcane residual biomass in Brazil. Energy Policy. 2011;39:421-8.

[22] Dantas GA, Legey LFL, Mazzone A. Energy from sugarcane bagasse in Brazil: An assessment of the productivity and cost of different technological routes. Renewable and Sustainable Energy Reviews. 2013;21:356-64.

[23] Khatiwada D, Seabra J, Silveira S, Walter A. Power generation from sugarcane biomass - A complementary option to hydroelectricity in Nepal and Brazil. Energy. 2012;48:241-54.

[24] Carpio LGT, Simone de Souza F. Optimal allocation of sugarcane bagasse for producing bioelectricity and second generation ethanol in Brazil: Scenarios of cost reductions. Renewable Energy. 2017;111:771-80.

[25] Moreira JR, Romeiro V, Fuss S, Kraxner F, Pacca SA. BECCS potential in Brazil: Achieving negative emissions in ethanol and electricity production based on sugar cane bagasse and other residues. Applied Energy. 2016;179:55-63. 
[26] Grisi EF, Yusta JM, Dufo-López R. Opportunity costs for bioelectricity sales in Brazilian sucro-energetic industries. Applied Energy. 2012;92:860-7.

[27] Möllersten K, Yan J, Westermark M. Potential and cost-effectiveness of CO2 reductions through energy measures in Swedish pulp and paper mills. Energy. 2003;28:691-710.

[28] Holmberg H, Tuomaala M, Haikonen T, Ahtila P. Allocation of fuel costs and CO2emissions to heat and power in an industrial CHP plant: Case integrated pulp and paper mill. Applied Energy. 2012;93:614-23.

[29] Pettersson K, Harvey S. CO2 emission balances for different black liquor gasification biorefinery concepts for production of electricity or second-generation liquid biofuels. Energy. 2010;35:1101-6.

[30] Bramstoft R, Pizarro Alonso A, Karlsson K, Kofoed-Wiuff A, Münster M. STREAM-an energy scenario modelling tool. Energy Strategy Reviews. 2018;21:62-70.

[31] Peter Witzke, Martin Banse, Horst Gömann, Thomas Heckelei, Thomas Breuer, Stefan Mann, et al. Modelling of Energy-Crops in Agricultural Sector Models - A Review of Existing Methodologies. In: Studies ECJRCIfPT, editor. Seville, Spain)2008.

[32] Wise M, Calvin K, Kyle P, Luckow P, Edmonds J. Economic and physical modeling of land use in gcam 3.0 and an application to agricultural productivity, land, and terrestrial carbon. Climate Change Economics. 2014;05:1450003.

[33] IEA-ETSAP. TIMES Optimization Modeling Documentation. 2018.

[34] Wiese F, Bramstoft R, Koduvere H, Pizarro Alonso A, Balyk O, Kirkerud JG, et al. Balmorel open source energy system model. Energy Strategy Reviews. 2018;20:26-34.

[35] Heaps CG. Long-range Energy Alternatives Planning (LEAP) system. In: Institute SE, editor. Somerville, MA, USA2016.

[36] Keramidas K, Kitous A, Després J, Schmitz A. POLES-JRC model documentation. In: (JRC) JRC, editor. Luxembourg2017.

[37] Lund H, Thellufsen JZ, Sorknæs P, Connolly D, Mathiesen BV, Østergaard PA, et al. EnergyPLAN Advanced Energy Systems Analysis Computer Model. In: Group SEPR, editor. Aalborg University, Denmark2017.

[38] McDonald S, Robinson S, Thierfelder K. Impact of switching production to bioenergy crops: The switchgrass example. Energy Economics. 2006;28:243-65.

[39] White EM, Latta G, Alig RJ, Skog KE, Adams DM. Biomass production from the U.S. forest and agriculture sectors in support of a renewable electricity standard. Energy Policy. 2013;58:64-74.

[40] Smeets EMW, Faaij APC, Lewandowski IM, Turkenburg WC. A bottom-up assessment and review of global bio-energy potentials to 2050. Progress in Energy and Combustion Science. 2007;33:56-106.

[41] Haberl H, Beringer T, Bhattacharya SC, Erb K-H, Hoogwijk M. The global technical potential of bio-energy in 2050 considering sustainability constraints. Current Opinion in Environmental Sustainability. 2010;2:394-403.

[42] Ricci O, Selosse S. Global and regional potential for bioelectricity with carbon capture and storage. Energy Policy. 2013;52:689-98.

[43] Oree V, Sayed Hassen SZ, Fleming PJ. Generation expansion planning optimisation with renewable energy integration: A review. Renewable and Sustainable Energy Reviews. 2017;69:790-803.

[44] Pérez Odeh R, Watts D, Flores Y. Planning in a changing environment: Applications of portfolio optimisation to deal with risk in the electricity sector. Renewable and Sustainable Energy Reviews. 2018;82:3808-23.

[45] Awerbuch S. Portfolio-Based Electricity Generation Planning: Policy Implications For Renewables And Energy Security. Mitigation and Adaptation Strategies for Global Change. 2006;11:693-710. 
[46] Markowitz H. Portfolio selection. The Journal of Finance. 1952;7:77-91.

[47] Artzner P, Delbaen F, Eber J-M, Heath D. Coherent Measures of Risk. Mathematical Finance. 1999;9:203-28.

[48] Rockafellar T, Uryasev S. Optimization of Conditional Value-at-Risk. Journal of Risk. 2000;2:21-41.

[49] Pflug GC. Some Remarks on the Value-at-Risk and the Conditional Value-at-Risk. In: Uryasev SP, editor. Probabilistic Constrained Optimization: Methodology and Applications. Boston, MA: Springer US; 2000. p. 272-81.

[50] Bar-Lev D, Katz S. A portfolio approach to fossil fuel procurement in the electric utility industry. The Journal of Finance. 1976;31:933-47.

[51] Awerbuch S, Yang S. Efficient electricity generating portfolios for Europe: maximising energy security and climate change mitigation. EIB Papers2007.

[52] Awerbuch S, Berger M. Applying portfolio theory to EU electricity planning and policymaking. In: Paper IEW, editor. Paris, France2003.

[53] Crow DJG, Giarola S, Hawkes AD. A dynamic model of global natural gas supply. Applied Energy. 2018;218:452-69.

[54] IBGE. Natural Resources and Environmental Studies - Coverage and Land Use (Recursos Naturais e Estudos Ambientais - Cobertura e Uso da Terra). In: Estatistica) BIoGaSIBdGe, editor. Brazil2018.

[55] UNICA. Unicadata - Brazilian Sugarcane Industry Association. In: http://www.unicadata.com.br/?idioma=2, editor. Brazil 2018.

[56] MME. PROBIO - Project for the conservation and sustainable use of Brazilian biological diversity (Projeto de conservação e utilização sustentável da diversidade biológica Brasileira), Ministry of the Environment (Ministerio de Meio Ambiente ). Brazil 2018.

[57] MAPA. Zoneamento Agroecológico da Cana-de-açúcar (ZAECana). In: Abastecimento MdAPe, editor. Rio de Janeiro, RJ, Brazil 2009. p. 58.

[58] García Kerdan I, Giarola S, Hawkes A. A novel energy systems model to explore the role of land use and reforestation in achieving carbon mitigation targets: A Brazil case study. Journal of Cleaner Production. 2019; 232: 796-821. .

[59] EIA. Assessing the Economic Value of New Utility-Scale Electricity Generation Projects. In: Administration USEI, editor. Independent Statistics \& Analysis2013.

[60] ANEEL. Tarifa de Uso da Transmissão, Brazilian Electric Energy National Agency. In: http://www.aneel.gov.br/metodologia-transmissao/, editor. Brazil 2016.

[61] EPE. Estudos para a licitação da expansão da geração (Studies for the bidding of generation expansion), Ministério de Minas e Energia. Brasília - DF, Brazil 2015.

[62] Elshurafa AM, Albardi SR, Bigerna S, Bollino CA. Estimating the learning curve of solar PV balance-of-system for over 20 countries: Implications and policy recommendations. Journal of Cleaner Production. 2018;196:122-34.

[63] Eletrobras. Eletrobras. In: https://eletrobras.com, editor. Brazil 2015.

[64] CRESEB. Atlas do Potencial Eólico Brasileiro. Brazil Centro de Referência para Energia Solar e Eólica Sérgio Brito; 2001.

[65] ONS. Operador Nacional do Sistema Eletrico (National Electrical System Operator) Histórico da operação. In: http://ons.org.br/paginas/resultados-da-operacao/historico-daoperacao, editor. Brazil 2018.

[66] Bodirsky BL, Rolinski S, Biewald A, Weindl I, Popp A, Lotze-Campen H. Global Food Demand Scenarios for the 21st Century. PLOS ONE. 2015;10:e0139201.

[67] Cirera X, Masset E. Income distribution trends and future food demand. Philosophical Transactions of the Royal Society B: Biological Sciences. 2010;365:2821-34. 
[68] Fricko O, Havlik P, Rogelj J, Klimont Z, Gusti M, Johnson N, et al. The marker quantification of the Shared Socioeconomic Pathway 2: A middle-of-the-road scenario for the 21st century. Global Environmental Change. 2017;42:251-67.

[69] Rochedo PRR, Soares-Filho B, Schaeffer R, Viola E, Szklo A, Lucena AFP, et al. The threat of political bargaining to climate mitigation in Brazil. Nature Climate Change. 2018;8:695-8.

[70] USDA-FAS. Brazil Sugar Annual, USDA Foreign Agricultural Service. USA 2017.

[71] Corrêa Neto V, Dan R. Análises de Opções Tecnológicas para Projetos de Cogeração no Setor Sucro-Alcooleiro (Analysis of Technological Options for Cogeneration Projects in the Sugar-Ethanol Sector), SETAP - Sustainable Energy Technology Assistance Program. Brasilia, Brazil USAID/Brazil and NREL; 2002.

[72] Walter A, Ensinas AV. Combined production of second-generation biofuels and electricity from sugarcane residues. Energy. 2010;35:874-9.

[73] Peng F, Ren J-L, Xu F, Bian J, Peng P, Sun R-C. Comparative Study of Hemicelluloses Obtained by Graded Ethanol Precipitation from Sugarcane Bagasse. Journal of Agricultural and Food Chemistry. 2009;57:6305-17.

[74] Liu G, Bao J. Evaluation of electricity generation from lignin residue and biogas in cellulosic ethanol production. Bioresource Technology. 2017;243:1232-6.

[75] Khatiwada D, Leduc S, Silveira S, McCallum I. Optimizing ethanol and bioelectricity production in sugarcane biorefineries in Brazil. Renewable Energy. 2016;85:371-86.

[76] IEA-Bioenergy. Black Liquor Gasification. Summary and Conclusions from the IEA Bioenergy ExCo54 Workshop In: IEA, editor.2007.

[77] Naqvi M, Yan J, Dahlquist E. Bio-refinery system in a pulp mill for methanol production with comparison of pressurized black liquor gasification and dry gasification using direct causticization. Applied Energy. 2012;90:24-31.

[78] IIP. Black liquor gasification In: Productivity IfI, editor. Industrial Efficiency Technology Database2010.

[79] IEA. International Energy Agency Statistics. In: https://www.iea.org/statistics/, editor.2017.

[80] INPE. Monitoramento da Floresta Amazônica Brasileira por Satélite. In: Brasil Gd, editor.2016.

[81] Bogaerts M, Cirhigiri L, Robinson I, Rodkin M, Hajjar R, Costa Junior C, et al. Climate change mitigation through intensified pasture management: Estimating greenhouse gas emissions on cattle farms in the Brazilian Amazon. Journal of Cleaner Production. 2017;162:1539-50.

[82] Barros MV, Piekarski CM, De Francisco AC. Carbon Footprint of Electricity Generation in Brazil: An Analysis of the 2016-2026 Period. Energies. 2018;11:1412.

[83] ANP. Agência Nacional de Petróleo, Gás Natural e Biocombustíveis, Renovabio, http://www.anp.gov.br/biocombustiveis/renovabio 2019.

[84] Naqvi M, Yan J, Dahlquist E. Black liquor gasification integrated in pulp and paper mills: A critical review. Bioresource Technology. 2010;101:8001-15.

[85] IEA. Black Liquor Gasification: Summary and Conclusions from the IEA Bioenergy ExCo54 Workshop In: Bioenergy I, editor.2007.

[86] EMBRAPA. Biomas do Brasil - Empresa Brasileira de Pesquisa Agropecuária (Embrapa). In: https://www.embrapa.br/contando-ciencia/biomas-do-brasil, editor. Brasil 2019. 